\title{
Tomato Transcriptional Responses to a Foliar and a Vascular Fungal Pathogen Are Distinct
}

\author{
H. Peter van Esse, ${ }^{1}$ Emilie F. Fradin, ${ }^{1}$ Philip J. de Groot, ${ }^{2}$ Pierre J. G. M. de Wit, ${ }^{1}$ and \\ Bart P. H. J. Thomma ${ }^{1}$ \\ ${ }^{1}$ Laboratory of Phytopathology, Centre for BioSystems Genomics (CBSG), Wageningen University, Binnenhaven 5, \\ 6709 PD Wageningen, The Netherlands; ${ }^{2}$ Nutrition, Metabolism and Genomics group, Division of Human Nutrition, \\ Wageningen University, Bomenweg 2, 6703 HD Wageningen, The Netherlands
}

Submitted 2 October 2008. Accepted 4 November 2008.

\begin{abstract}
Plant activation of host defense against pathogenic microbes requires significant host transcriptional reprogramming. In this study, we compared transcriptional changes in tomato during compatible and incompatible interactions with the foliar fungal pathogen Cladosporium fulvum and the vascular fungal pathogen Verticillium dahliae. Although both pathogens colonize different host tissues, they display distinct commonalities in their infection strategy; both pathogens penetrate natural openings and grow strictly extracellular. Furthermore, resistance against both pathogens is conveyed by the same class of resistance proteins, the receptor-like proteins. For each individual pathogen, the expression profile of the compatible and incompatible interaction largely overlaps. However, when comparing between the two pathogens, the $C$. fulvum-induced transcriptional changes show little overlap with those induced by $V$. dahliae. Moreover, within the subset of genes that are regulated by both pathogens, many genes show inverse regulation. With pathway reconstruction, networks of tomato genes implicated in photorespiration, hypoxia, and glycoxylate metabolism were identified that are repressed upon infection with $C$. fulvum and induced by $V$. dahliae. Similarly, auxin signaling is differentially affected by the two pathogens. Thus, differentially regulated pathways were identified with novel strategies that allowed the use of state-of-the-art tools, even though tomato is not a genetic model organism.
\end{abstract}

Plants are continuously exposed to microbial pathogens that aim to parasitize them. In response to this threat, plants have evolved various defense mechanisms to protect themselves against microbial attack. These mechanisms comprise constitutive defense barriers and defenses that are activated upon detection of a potential invader. Regardless of whether or not a pathogen is arrested in growth, microbial attack generally leads to significant host transcriptional reprogramming. A few decades ago, the first pathogenesis-related $(P R)$ genes were identified that are induced by pathogen attack and of which the corresponding gene products have been associated with pathogen defense (van Loon and van Strien 1999). Apart from basal

H. P. van Esse and E. F. Fradin contributed equally to this work.

Corresponding author: B. P. H. J. Thomma; Telephone: +1 0031-317484536; Fax:+1 0031-317-483412; E-mail: bart.thomma@wur.nl

* The $\boldsymbol{e}$-Xtra logo stands for "electronic extra" and indicates that two supplemental figures and seven supplemental tables are published online. defense, PR proteins also play a role in race-specific disease resistance (Thomma et al. 2001; Thordal-Christensen 2003), demonstrating that both types of defense responses at least partly employ the same defense genes. More recently, transcriptional reprogramming has been monitored at a genome-wide scale in a growing number of plant species with the use of microarrays (Quirino and Bent 2003; van Baarlen et al. 2008; Wise et al. 2007). Plant microarray data generally demonstrate that, in the interactions of plant pathogens with their hosts, hundreds of genes are activated and repressed. Most microarray analyses are initiated for gene discovery in order to associate novel genes with effective host defense responses or as a lead to select appropriate candidate genes for functional analysis (Wan et al. 2002; Wise et al. 2007). Alternatively, microarray analyses can be used to profile the transcriptional activity of a plant tissue, providing global insight into host cell biology (Bolton et al. 2008a; van Baarlen et al. 2008; van Esse et al. 2008). Such an approach facilitates visualization of underlying biological processes (van Baarlen et al. 2008). The shared expression patterns of characterized plant genes and genes with unknown functions may suggest biological functions of the "unknown" genes. Furthermore, expression-profile comparison at the level of cellular pathways may lead to novel hypotheses concerning the biology of the interaction which, after experimental verification, can provide further insight into decisive elements that have roles in cellular processes (van Baarlen et al. 2008). Although still in its infancy in plants, this strategy has been exploited successfully in several other biological systems (Kobayashi et al. 2003; van Baarlen et al. 2008).

It has been suggested that a plant is resistant or susceptible to a specific pathogen depending on the speed and rate at which the same host defense molecules are produced, suggesting that resistance is based on quantitative rather than qualitative differences in host defense (Eulgem et al. 2004; Navarro et al. 2004; Tao et al. 2003; Thilmony et al. 2006). However, others have observed significantly divergent gene expression not only between compatible and incompatible interactions (Caldo et al. 2004) but also between incompatible interactions of the same pathogen-host combination that are mediated by different resistance (R) proteins (Adams-Philips et al. 2008).

Until recently, the vast amount of microarray data was generated for the model plant species Arabidopsis, and most transcriptomics studies upon pathogen attack relied on inoculations with the bacterium Pseudomonas syringae (Maleck et al. 2000; Scheideler et al. 2002), the fungus Alternaria brassicicola (Schenk et al. 2000; van Wees et al. 2003), and the oomycete Hyaloperonospora parasitica (Eulgem et al. 2004; Maleck et al. 2000). However, high-density microarrays are currently 
available for a growing set of crop species (Wise et al. 2007), including the Solanaceous crop plant tomato (van Esse et al. 2007).

In this study, we performed global transcriptional profiling to compare transcriptional changes in tomato during compatible and incompatible interactions with the fungal pathogens Cladosporium fulvum and Verticillium dahliae. Both pathogens have fundamentally different infection strategies because C. fulvum is a foliar pathogen that causes leaf mold on its sole host tomato (Thomma et al. 2005), whereas $V$. dahliae is a soilborne vascular pathogen of over 200 host plants (Fradin and Thomma 2006). Despite these differences in their infection strategies, both pathogens share a number of characteristics because they invade their host through natural openings and grow strictly extracellular without the formation of feeding structures such as haustoria (Fradin and Thomma 2006; Thomma et al. 2005). Furthermore, in incompatible interactions with tomato, recognition of these pathogens is mediated by plasma membrane-anchored extracellular receptor proteins that belong to the receptor-like protein class of resistance proteins (Fradin and Thomma 2006; Jones et al. 1994; Kawchuk et al. 2001; Thomma et al. 2005). The aim of this study was to compare global transcriptional profiles in response to host attack by $C$. fulvum and $V$. dahliae in order to identify differences and similarities in compatible and incompatible interactions with a foliar and a vascular fungal pathogen.
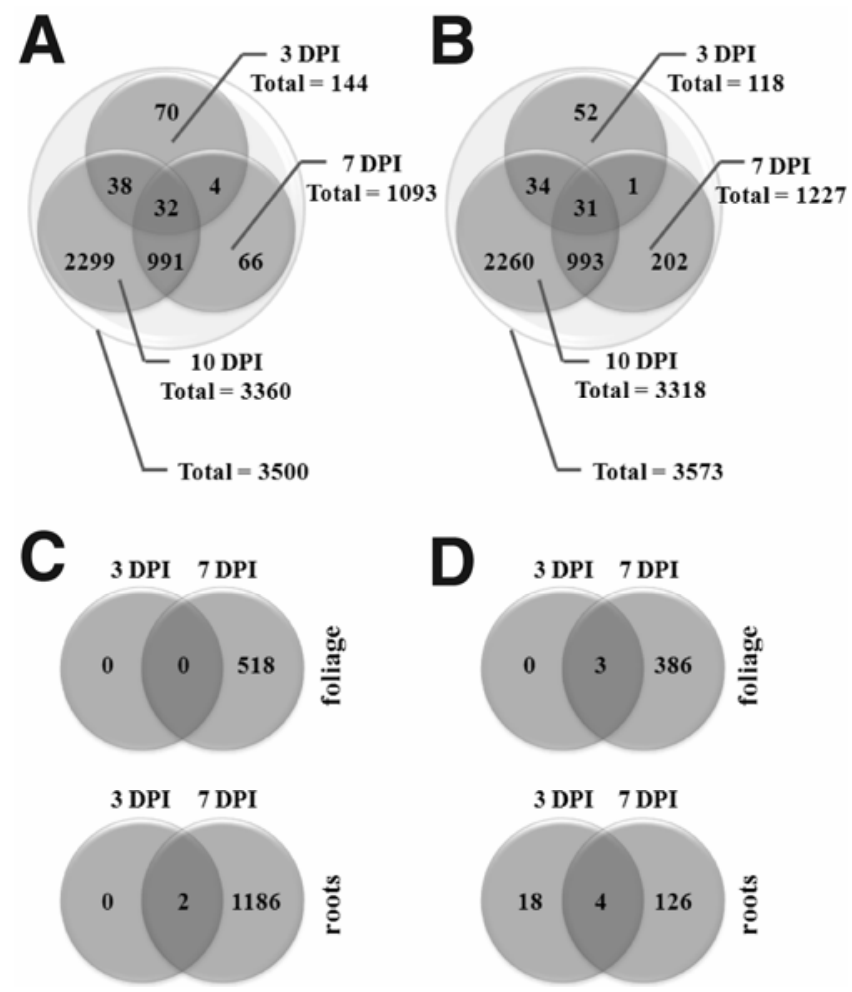

Fig. 1. Differentially regulated tomato genes during compatible and incompatible interactions with Cladosporium fulvum and Verticillium dahliae. A, Venn diagram displaying overlap in differentially regulated genes between different time points of the compatible C. fulvum-tomato interaction. B, Venn diagram displaying overlap in differentially regulated genes between different time points of the incompatible C. fulvum-tomato interaction. $\mathbf{C}$, Venn diagram displaying overlap in differentially regulated genes between different time points of the compatible $V$. dahliae-tomato interaction in roots and in foliage. $\mathbf{D}$, Venn diagram displaying overlap in differentially regulated genes between different time points of the incompatible $V$. dahliae-tomato interaction in roots and in foliage.

\section{RESULTS}

Transcriptional changes in tomato upon $C$. fulvum inoculation.

We have previously shown that, in a compatible interaction, the fungus colonizes the apoplast around leaf mesophyll cells and, by 10 days postinoculation (DPI), clear symptoms of disease are visible as chlorosis and conidiophores that emerge from stomata on the lower side of the leaves (Bolton et al. 2008b). After 10 DPI, leaf tissues start to necrotize. Using real-time polymerase chain reaction (PCR) to quantify fungal biomass in the plant tissue, it is evident that fungal biomass gradually increases until the fungus is extensively sporulating (Bolton et al. 2008b). Tomato genes that were differentially regulated (more than twofold change with a $P$ value $\leq 0.001$ ) upon inoculation with $C$. fulvum were identified at 3,7 , and 10 DPI using samples harvested at 0 DPI as the reference samples to which the samples from all other timepoints were compared (Fig. 1A). Fungal presence in the samples of the compatible interaction was verified with real-time PCR (Supplementary Fig. 1A). In the compatible interaction, the number of differentially induced genes amounted to 144, 1,093, and 3,360 genes at 3, 7, and $10 \mathrm{DPI}$, respectively (Fig. 1A). A small subset of only 32 genes was found to be differentially regulated throughout the three timepoints (Fig. 1A; Supplementary Table 1). In the incompatible interaction, 118, 1,227 and 3,318 genes were differentially regulated at 3, 7, and 10 DPI, respectively (Fig. 1B). Thus, although the fungus is arrested soon after tissue penetration in the incompatible interaction, the number of differentially regulated genes is comparable with that in the compatible interaction. Moreover, a similarly low number of genes $(n=31)$ was differentially regulated at the three timepoints throughout the incompatible interaction (Fig. 1B).

Often, similar gene sets are induced during compatible and incompatible plant-pathogen interactions, albeit that the regulation occurs with different rates and amplitudes (Eulgem et al. 2004; Navarro et al. 2004; Tao et al. 2003; Thilmony et al. 2006). To account for temporal variation, the differentially regulated genes monitored at the different timepoints were pooled to one gene set of 3,500 genes for the compatible and one set of 3,573 genes for the incompatible interaction (Fig. 1A and B). Roughly two-thirds of the regulated genes overlapped between both interactions (Fig. 2A). Subsequently, hierarchical clustering (HCL) (Eisen et al. 1998) was performed to cluster genes based on similarity in expression patterns, revealing that most overlapping genes displayed similar expression patterns over time in the compatible and incompatible interaction (Fig. 2B).

For tomato, a whole-genome sequence is not yet available, and gene annotation and information is still limited. Because many tomato genes are still of unknown function, obtaining insight into the underlying biology of microarray experiments is difficult. A starting point to explore poorly characterized genes and predict plant protein function is the use of Gene Ontology (GO) annotation (The Gene Ontology Consortium 2000), a controlled formal vocabulary that consists of general terms for gene and protein annotation in any organism, making comparisons across taxa possible (van Baarlen et al. 2008). Therefore, we decided to perform an orthology prediction for all 22,721 gene transcripts that can be probed by the GeneChip, and were able to assign GO annotations to 6,730 of these transcripts. These were used to identify the major differentially regulated biological processes (Table 1), showing that most differentially regulated genes belong to the categories transport, metabolism, and phosphorylation. Interestingly, despite the observation that only two-thirds of the regulated genes appeared to overlap for both interactions, no significant differ- 
ences were observed in differentially regulated biological processes between the compatible and the incompatible interaction (Table 1).

\section{Transcriptional changes in tomato upon $V$. dahliae inoculation.}

As for the foliar pathogen C. fulvum, transcriptional changes were monitored in tomato upon inoculation with the vascular pathogen $V$. dahliae (more than twofold change with a $P$ value $\leq 0.001$ ). Because $V$. dahliae is a soilborne pathogen, samples were taken of foliage (leaves and stems) and of roots at 3 and 7 DPI. Compared with inoculation with $C$. fulvum, display of typical symptoms of disease occurred faster upon inoculation with $V$. dahliae; by 7 DPI, clear stunting of plants and chlorosis was observed. At 10 DPI, disease symptoms were very severe and necrosis was observed. Therefore, this timepoint was not included in the assay. Fungal presence in the samples of the compatible interaction was verified with real-time PCR, showing a continuous increase in fungal biomass in the roots whereas, in foliage, the biomass increased by 3 DPI and decreased by 7 DPI. This agrees with previous observations of peaks of Verticillium spp. growth at 2 to 4 days and 12 to 15 DPI, succeeded by intermittent periods of fungal elimination (Heinz et al. 1998). V. dahliae inoculation requires uprooting of the plants followed by root-dip inoculation. This method is likely to introduce transcriptional changes that are not related to pathogen attack; therefore, mock-inoculated plants harvested at 3 DPI were taken as the reference to which all other samples were compared. In the compatible interaction, 0 and 2 genes were found to be differentially regulated at 3 DPI in foliage and roots, respectively, whereas, at 7 DPI, 518 and 1,188 genes were differentially regulated in those tissues (Fig. 1C and D). In the incompatible interaction, 3 and 22 genes were differentially regulated at 3 DPI while 389 and 130 genes were differentially regulated at 7 DPI in the foliage and roots, respectively (Fig. 1C and D). Remarkably, in roots, the number of differentially expressed genes in the compatible interaction was almost 10 -fold the number of differentials in the incompatible interaction. Thus, in contrast to the $C$. fulvum-induced transcriptional changes, the $V$. dahliae-induced transcriptional changes concern significantly more genes in the compatible interaction than in the incompatible interaction.

As for the C. fulvum-tomato analyses, temporal variation was countered by pooling the transcriptional changes monitored in samples harvested at 3 and 7 DPI for each interaction. Overall, in the foliage, 280 genes were identified in the overlap between the total of 518 and 389 differentially regulated genes in the compatible and incompatible interaction, respectively
A

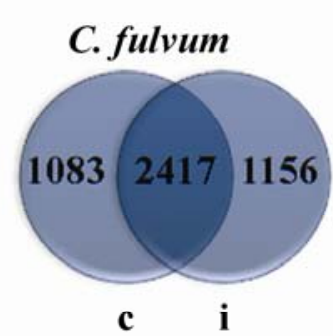

B

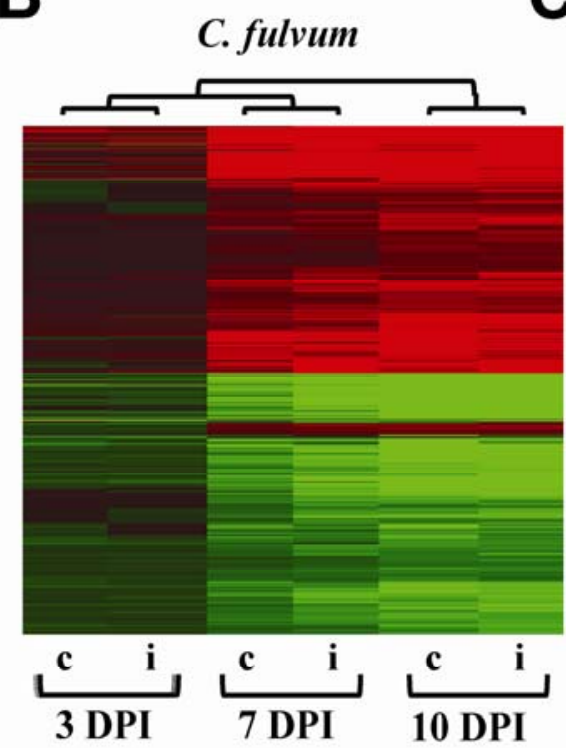

V. dahliae
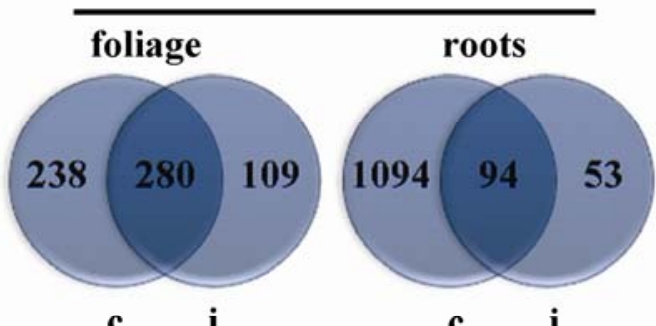

c i

\section{C}
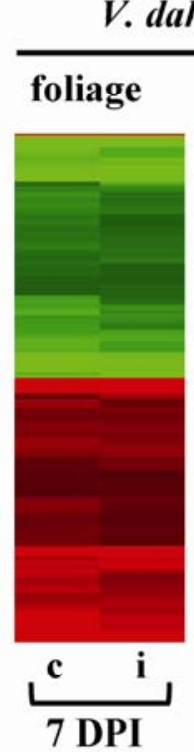

D

\section{V. dahliae}

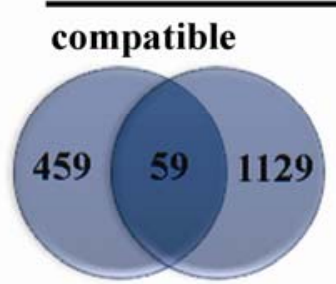

f

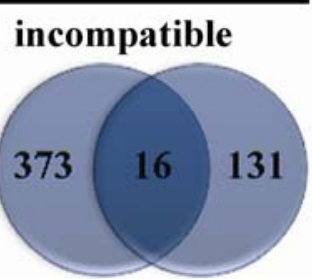

f $\quad \mathbf{r}$

\section{V. dahliae}

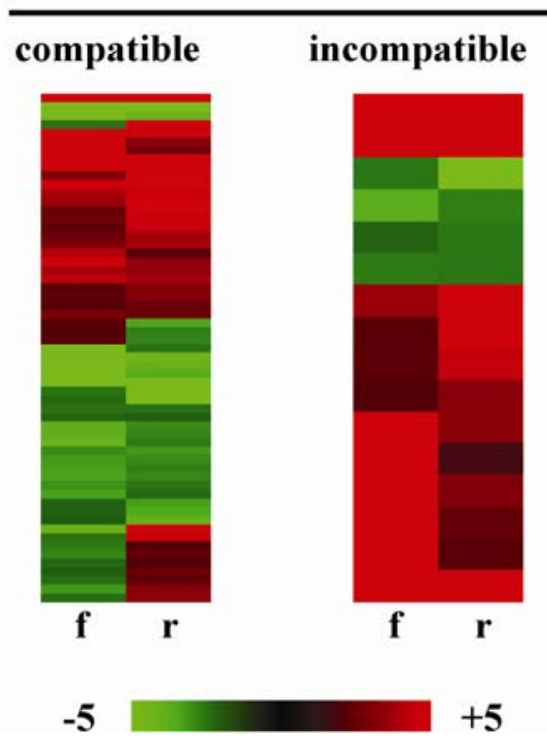

Fig. 2. Comparison of differentially regulated tomato gene sets during interactions with Cladosporium fulvum and Verticillium dahliae. A, Venn diagrams displaying specificity and overlap in differentially regulated gene sets between compatible (c) and incompatible (i) interactions with tomato. B, Expression profiles of differentially regulated genes in the compatible (c) and incompatible (i) C. fulvum-tomato interaction at 3, 7, and 10 days postinoculation (DPI), respectively. C, Expression profiles of differentially regulated genes in foliage and roots in the compatible (c) and incompatible (i) V. dahliae-tomato interaction at 7 DPI in foliage and roots. D, Venn diagrams displaying specificity and overlap in differentially regulated gene sets of the compatible and incompatible $V$. dahliae-tomato interaction between foliage (f) and roots (r). E, Expression profiles of differentially regulated genes in the compatible and incompatible V. dahliae-tomato interaction between foliage (f) and roots (r). 
(Fig. 2A). In roots, 94 genes were identified in the overlap between the 1,188 and 147 differentially regulated genes of the compatible and incompatible interactions, respectively (Fig. 2A). As for C. fulvum, HCL showed that most overlapping genes displayed similar expression patterns over time in the compatible and incompatible interactions (Fig. 2C). The assessment of $\mathrm{GO}$ categories for the $V$. dahliae-regulated genes showed only minor differences between the compatible and incompatible interactions (Table 1).

\section{Comparison of transcriptional changes in foliage and roots upon $\boldsymbol{V}$. dahliae inoculation.}

$V$. dahliae is a soilborne pathogen that penetrates the roots and travels through the vascular system toward the green tissues. When comparing the transcriptional changes in roots and foliage, a rather small overlap was observed (Fig. 2D). For the compatible interaction, 59 genes overlapped whereas, for the incompatible interaction, only 16 genes overlapped between the differentially regulated gene sets for roots and foliage (Fig. 2D; Supplementary Table 2). In the overlapping gene set of the compatible interaction, the $P R$ genes encoding P69B, PR-5, and hevein-like protein, a homolog of the Arabidopsis monosaccharide symporter STP6 gene (Scholz-Starke et al. 2003), and several aquaporin $\delta$-TIP genes that are implied in osmotic housekeeping (Daniels et al. 1996) were induced in both tissue types, while the TAS14 dehydrin gene was strongly repressed. Of the 59 genes, 13 genes displayed an inverse expression pattern between roots and foliage (Fig. 2E), among which was a homologue of the tobacco nitrate reductase nir-3 gene (Kronenberger et al. 1993) that was induced in foliage and repressed in roots. Highly induced foliage-specific genes upon $V$. dahliae inoculation included photosynthesis genes, aquaporin $\delta$-TIP genes (Daniels et al. 1996), genes implicated in salt tolerance (Nagaoka and Takano 2003), an ammonium transporter gene, and a nitrate transporter gene. Interestingly, root-specific induced genes included the $P R$ genes $P R l a, P R-5 x$, and $P 96 F$, but also the Pipl and Rcr3 genes that are induced upon infection with $C$. fulvum and Phytophthora infestans (Krüger et al. 2002; Tian et al. 2007; van Esse et al. 2008). Other root-specific induced genes were the inorganic phosphate transporter gene LePT2, the iron transporter gene LeIRT1 (Eckhardt et al. 2001), and an Arabidopsis copper transporter gene homolog. In the incompatible interaction, the overlap between the transcriptional changes of the roots and foliage consisted of only 16 genes with similar expression patterns (Fig. 2D and E) that included the $P R$ gene $P R-5 x$ and chitinase genes. Genes involved in proteolysis and transcription were induced in foliage but not in roots, as was the case for the pathogen-inducible Rcr3, Pipl, and P69B genes. In roots, the iron transporter gene
LeIRT1 (Eckhardt et al. 2001) was induced. Overall, it can be concluded that the transcriptional changes in root and foliar tissues of tomato upon $V$. dahliae inoculation are highly distinct.

\section{Transcriptional changes \\ upon $C$. fulvum and V. dahliae inoculation differ.}

Although $C$. fulvum and $V$. dahliae colonize different host tissues, both pathogens have several commonalities in their infection strategies because they only penetrate natural openings and grow strictly extracellular without the formation of haustoria. However, during compatible interactions with tomato, the major differentially regulated biological processes by these pathogens differed (Table 1). Interestingly, C. fulvum-induced transcriptional changes in foliar tissues more resembled $V$. dahliae-induced transcriptional changes in root tissues than those monitored in foliar tissues (Table 1). Nevertheless, the percentages of genes related to transport and proteolysis (the class that also contains many $P R$ genes) were larger in roots during the compatible interaction with $V$. dahliae than with $C$. fulvum, whereas the percentage of genes related to metabolism was larger in the compatible interaction with $C$. fulvum than in V. dahliae-infected roots.

For both $C$. fulvum and $V$. dahliae, resistance in incompatible interactions is conveyed by extracellular transmembrane receptors that belong to the class of receptor-like proteins (Fradin and Thomma 2006; Thomma et al. 2005). It may be anticipated that pathogen receptors that belong to the same class converge into the same signal transduction cascade that mediates a defense response. In such cases, the transcriptional changes are expected to largely overlap. Nevertheless, overall, considerable differences are observed in the major regulated biological processes in both incompatible interactions (Table 1).

To study the $C$. fulvum- and $V$. dahliae-induced transcriptional changes in more detail, we compared the 3,500 C. fulvumregulated genes with the 1,647 $\mathrm{V}$. dahliae-regulated genes in the roots and foliage for both compatible interactions, showing that the overlap contained only 454 genes (Fig. 3A; Supplementary Table 3). Similarly, both incompatible interactions were compared, showing only 172 overlapping genes (Fig. $3 \mathrm{~A})$. When the differentially C. fulvum-regulated genes at 10 DPI were removed from the analysis, the overlap was even smaller, with 160 and 74 genes for the compatible and incompatible interactions, respectively (Supplementary Fig. 2). The C. fulvum-specific genes in both the compatible and incompatible interaction included many glutathione S-transferase genes which are implicated in attenuation of the oxidative burst (Lamb and Dixon 1997) (Supplementary Table 4). Furthermore, many WRKY transcription factor genes were specifically regulated in the $C$. fulvum-tomato interaction (12 in

Table 1. Differentially regulated biological processes (Gene Ontology [GO] process) identified in the diverse interactions of tomato with Cladosporium fulvum and Verticillium dahliae

\begin{tabular}{|c|c|c|c|c|c|c|}
\hline \multirow[b]{3}{*}{ GO process } & \multicolumn{6}{|c|}{ Differentially expressed genes $(\%)^{\mathrm{a}}$} \\
\hline & \multicolumn{2}{|c|}{ C. fulvum foliage } & \multicolumn{2}{|c|}{ V. dahliae foliage } & \multicolumn{2}{|c|}{ V. dahliae roots } \\
\hline & Compatible & Incompatible & Compatible & Incompatible & Compatible & Incompatible \\
\hline Biosynthesis & 11 & 11 & 9 & 10 & 9 & 36 \\
\hline Metabolism & 29 & 29 & 23 & 24 & 22 & 21 \\
\hline Phosphorylation & 13 & 12 & 7 & 5 & 11 & 7 \\
\hline Photosynthesis & 4 & 3 & 6 & 4 & 2 & 0 \\
\hline Proteolysis & 7 & 8 & 7 & 9 & 10 & 0 \\
\hline Response to stress & 4 & 4 & 9 & 7 & 3 & 2 \\
\hline Transcription & 4 & 5 & 5 & 2 & 4 & 0 \\
\hline Transport & 26 & 25 & 29 & 33 & 35 & 25 \\
\hline Signal transduction & 1 & 1 & 2 & 2 & 2 & 2 \\
\hline Cell wall & 2 & 2 & 3 & 4 & 2 & 7 \\
\hline
\end{tabular}

${ }^{a}$ Values refer to the percentage (of the total number) of differentially expressed genes for which a GO annotation could be assigned. 
the compatible and 18 in the incompatible interaction), whereas no regulation of WRKY transcription factor genes was monitored in the interactions with $V$. dahliae. Similarly, no apical meristem (NAM)-like proteins were found to be specifically induced in the $C$. fulvum-tomato interaction (6 in the compatible and 10 in the incompatible interaction). Unique $V$. dahliaeregulated genes in both the compatible and incompatible interaction included genes that encode osmotic housekeeping factors, such as $\delta$-tonoplast intrinsic aquaporins (Kjellbom et al. 1999), salt tolerance-like proteins, and a homologue of the SOS2 salt tolerance protein (Liu et al. 2000). In addition, an inorganic phosphate transporter (Daram et al. 1998) and ironregulated transporter 1 (Eckhardt et al. 2001) were highly induced in root tissue.

K-Means clustering (Soukas et al. 2000) was performed on the overlapping genes (Fig. 3B) to group genes with a similar expression pattern. Between the C. fulvum- and $V$. dahliaeinduced transcriptional changes, we identified 51 induced and 17 repressed genes in both compatible interactions. Similarly, 35 and 2 genes were induced and repressed, respectively, in both incompatible interactions. As may be expected, $P R$ genes

\section{A compatible}

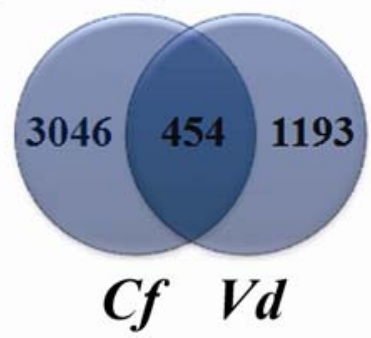

B

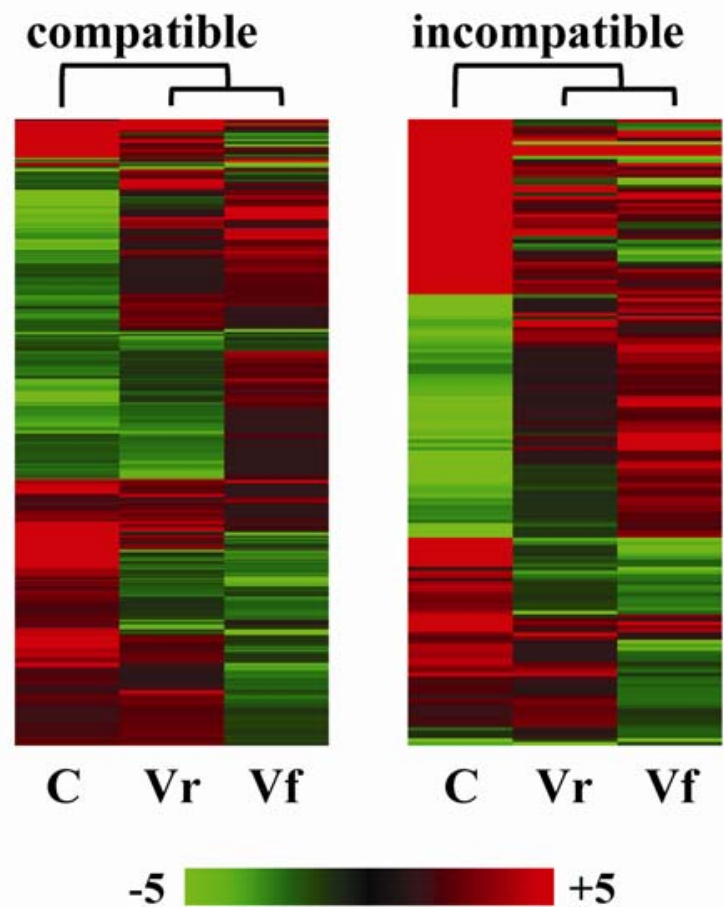

Fig. 3. Cladosporium fulvum and Verticillium dahliae induce largely different transcriptional changes. A, Venn diagrams displaying specificity and overlap in compatible and incompatible tomato interactions with $C$. fulvum $(C f)$ and $V$. dahliae $(V d)$. B, Expression profiles of differentially regulated genes in compatible and incompatible tomato interactions with C. fulvum-infected tomato (C) and V. dahliae-infected foliar (Vf) and root (Vr) tissues at 7 days postinoculation. were induced in all interactions. HCL on the subsets of overlapping genes for the compatible but also for the incompatible interaction showed that most of the differentially regulated genes in $V$. dahliae-infected roots tissues displayed a regulation similar to that in $C$. fulvum-infected leaves, whereas the same genes showed an inverse regulation in the $V$. dahliaeinfected foliage (Fig. 3B).

Overall, our results show that the transcriptional response of tomato toward both pathogens is completely different. Within the 454 differentially regulated genes that were shared between both compatible pathogen interactions, 164 genes displayed an inverse expression pattern, consisting of 62 genes that were induced by $C$. fulvum and repressed by $V$. dahliae and 102 genes that were repressed by $C$. fulvum and induced by $V$. dahliae (Fig. 3). A similar situation was true for the incompatible interactions, for which 72 of the 172 shared differentials displayed inverse regulation (Fig. 3). Remarkably, of the 102 inversely regulated genes in the compatible interactions, 16 genes could be implied in photosynthesis. To further investigate the effect of both pathogens on photosynthesis, HCL was performed on the 41 photosynthesis genes represented on the GeneChip by plotting the response of these 41 genes to $C$. fulvum and $V$. dahliae infection at the various timepoints (Fig. 4; Supplementary Table 5). Strikingly, most of these 41 genes were inversely regulated upon inoculation with the two pathogens. This strongly suggests that, upon $C$. fulvum infection, photosynthesis is repressed, while $V$. dahliae infection induces photosynthesis genes in both the compatible and incompatible interactions (Fig. 4).

\section{Over-representation analysis}

\section{identifies regulated cellular processes.}

Over-representation analysis (ORA) can detect over- or under-representation of gene categories in a data set when compared with a reference data set while correcting for chance (Backes et al. 2007). A powerful web-based tool to perform ORA is GeneTrail (Backes et al. 2007), which is able to use

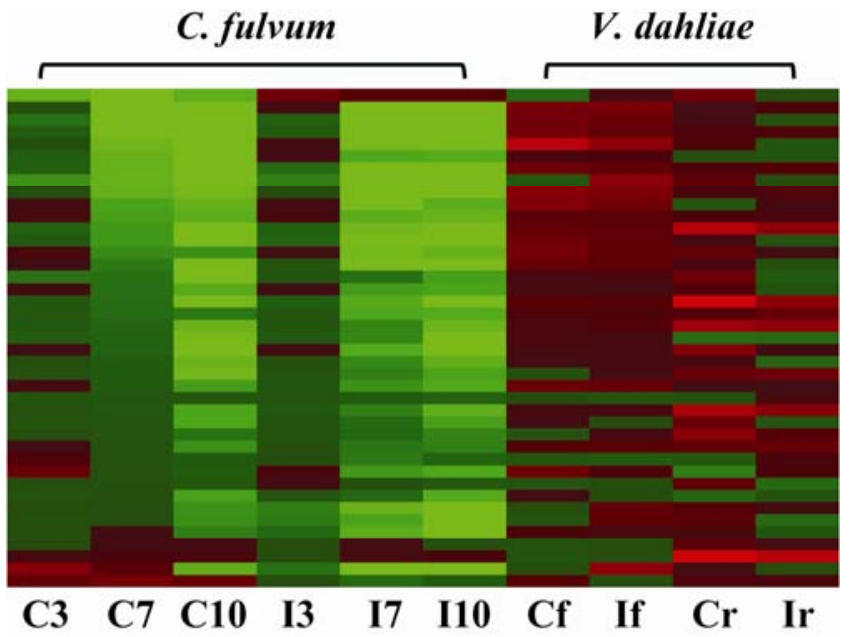

\section{$-3+3$}

Fig. 4. Cladosporium fulvum and Verticillium dahliae have inverse effects on photosynthesis. Transcriptional regulation of the 41 photosynthesis genes that are represented on the tomato GeneChip in the interactions of tomato with $C$. fulvum and $V$. dahliae at various time points. The different lanes represent the compatible tomato interaction with C. fulvum at 3, 7, and 10 days postinoculation (DPI) (C3, C7, and C10, respectively), the incompatible interaction with C. fulvum at the same time points (I3, I7, and I10, respectively), the compatible and incompatible tomato interaction with $V$. dahliae in foliage at 7 DPI (Cf and If, respectively), and the compatible and incompatible tomato interaction with $V$. dahliae in roots at 7 DPI (Cr and Ir, respectively). 
Arabidopsis Reference Sequence (RefSeq) identifiers as input. Therefore, all tomato genes that are monitored with the GeneChip were BLASTed against the National Center for Biotechnology Information (NCBI) RefSeq database (Pruitt et al. 2005) to identify the closest Arabidopsis homologue. For the ORA, we only considered tomato genes for which an Arabidopsis homologue with significant similarity could be identified $\left(E\right.$ value $\left.\leq 1 \times 10^{-6}\right)$. Therefore, only 15,835 of the 22,721 genes that are monitored with the GeneChip were used in the ORA. As expected, ORA on repressed genes in the C. fulvumtomato interactions (false discovery rate $<0.01$ ) identified photosynthetic processes (Table 2; Supplementary Table 6). Interestingly, for the compatible interaction, the ORA suggests that the major defense response to $V$. dahliae occurs in roots whereas, in the foliage, the over-represented gene categories concern housekeeping and metabolism. Due to the low number

Table 2. Over-representation analysis of differentially regulated genes during the compatible Cladosporium fulvum-tomato interaction

\begin{tabular}{|c|c|}
\hline Gene Ontology subcategory ${ }^{a}$ & $P$ value ${ }^{\text {b }}$ \\
\hline \multicolumn{2}{|l|}{ C. fulvum-tomato induced categories } \\
\hline Response to other organism & $1.40 \mathrm{E}-10$ \\
\hline Response to biotic stimulus & $5.70 \mathrm{E}-10$ \\
\hline Multi-organism process & $1.50 \mathrm{E}-09$ \\
\hline Defense response & 7.10E-07 \\
\hline Response to bacterium & $1.40 \mathrm{E}-06$ \\
\hline Immune system process & $2.60 \mathrm{E}-06$ \\
\hline Immune response & $2.60 \mathrm{E}-06$ \\
\hline Response to stimulus & $8.20 \mathrm{E}-06$ \\
\hline Defense response to bacterium & $1.20 \mathrm{E}-05$ \\
\hline Defense response, incompatible interaction & $1.20 \mathrm{E}-05$ \\
\hline Innate immune response & $1.20 \mathrm{E}-05$ \\
\hline Cellular catabolic process & $2.00 \mathrm{E}-05$ \\
\hline Catabolic process & $7.90 \mathrm{E}-05$ \\
\hline Response to wounding & $8.10 \mathrm{E}-05$ \\
\hline Response to fungus & $1.00 \mathrm{E}-04$ \\
\hline Response to SA stimulus & $3.30 \mathrm{E}-04$ \\
\hline Toxin catabolic process & 3.30E-04 \\
\hline Toxin metabolic process & 3.30E-04 \\
\hline SA-mediated signaling pathway & $3.30 \mathrm{E}-04$ \\
\hline SAR, SA-mediated signaling pathway & $7.20 \mathrm{E}-04$ \\
\hline Defense response to fungus & $8.90 \mathrm{E}-04$ \\
\hline Biopolymer modification & $8.90 \mathrm{E}-04$ \\
\hline Response to chemical stimulus & $1.10 \mathrm{E}-03$ \\
\hline Response to external stimulus & $1.10 \mathrm{E}-03$ \\
\hline JA- and ethylene-dependent systemic resistance & $1.10 \mathrm{E}-03$ \\
\hline Protein modification process & $1.20 \mathrm{E}-03$ \\
\hline JA-mediated signaling pathway & $1.40 \mathrm{E}-03$ \\
\hline Response to JA stimulus & $1.50 \mathrm{E}-03$ \\
\hline SAR & $2.50 \mathrm{E}-03$ \\
\hline Proteolysis & $2.70 \mathrm{E}-03$ \\
\hline Response to toxin & $2.70 \mathrm{E}-03$ \\
\hline Response to stress & $3.10 \mathrm{E}-03$ \\
\hline Integral to plasma membrane & $3.10 \mathrm{E}-03$ \\
\hline Potassium ion transport & $3.30 \mathrm{E}-03$ \\
\hline Endomembrane system & $3.70 \mathrm{E}-03$ \\
\hline Post-translational protein modification & $3.80 \mathrm{E}-03$ \\
\hline Protein amino acid phosphorylation & $4.50 \mathrm{E}-03$ \\
\hline Intrinsic to plasma membrane & $5.60 \mathrm{E}-03$ \\
\hline Glutathione transferase activity & $7.00 \mathrm{E}-03$ \\
\hline Catalytic activity & $7.60 \mathrm{E}-03$ \\
\hline \multicolumn{2}{|l|}{ C. fulvum-tomato repressed categories } \\
\hline Chloroplast & $4.00 \mathrm{E}-108$ \\
\hline Plastid part & $7.10 \mathrm{E}-67$ \\
\hline Cytoplasmic part & $2.50 \mathrm{E}-64$ \\
\hline Chloroplast part & $2.20 \mathrm{E}-60$ \\
\hline Cytoplasm & $2.80 \mathrm{E}-60$ \\
\hline Thylakoid & $4.60 \mathrm{E}-52$ \\
\hline
\end{tabular}

${ }^{\mathrm{a}} \mathrm{SA}=$ salicylic acid, $\mathrm{SAR}=$ systemic acquired resistance, and JA $=$ jasmonic acid.

${ }^{\mathrm{b}}$ False discovery rate. of differentially regulated genes in roots during the incompatible interaction, no overrepresented categories are identified.

Based on gene expression data (Fig. 3B), the compatible $C$. fulvum-tomato interaction most resembled the compatible $V$. dahliae-tomato interaction in roots. ORA of these data sets showed that categories such as "defense response, incompatible interaction", "defense response against fungus", and "response to biotic stimulus" are indeed over-represented in both gene sets (Tables 2 and 3). Nevertheless, many of the genes that are activated in these categories are different between the two interactions (Supplementary Table 7). However, most of the over-represented categories are unique for either the $C$. fulvum- or V. dahliae-tomato interaction. Remarkably, two categories that are over-represented in the C. fulvum-tomato interaction but not in the $V$. dahliae-tomato interaction are "defense response to bacterium" and "response against bacterium" con-

Table 2. (continued from preceding column)

\begin{tabular}{|c|c|}
\hline Gene Ontology subcategory & $P$ value $^{b}$ \\
\hline \multicolumn{2}{|c|}{ C. fulvum-tomato repressed categories (Continued) } \\
\hline Plastid thylakoid & $2.90 \mathrm{E}-51$ \\
\hline Chloroplast thylakoid & $5.90 \mathrm{E}-51$ \\
\hline Organelle subcompartment & $1.10 \mathrm{E}-50$ \\
\hline Thylakoid part & $2.80 \mathrm{E}-49$ \\
\hline Chloroplast thylakoid membrane & $1.50 \mathrm{E}-46$ \\
\hline Plastid thylakoid membrane & $1.50 \mathrm{E}-46$ \\
\hline Intracellular membrane-bound organelle & $1.80 \mathrm{E}-46$ \\
\hline Membrane-bound organelle & $1.90 \mathrm{E}-46$ \\
\hline Thylakoid membrane & $3.40 \mathrm{E}-46$ \\
\hline Intracellular organelle & $1.40 \mathrm{E}-45$ \\
\hline Organelle & $1.60 \mathrm{E}-45$ \\
\hline Cell part & $5.10 \mathrm{E}-41$ \\
\hline Cell & $5.10 \mathrm{E}-41$ \\
\hline Intracellular part & $4.60 \mathrm{E}-38$ \\
\hline Intracellular & $1.60 \mathrm{E}-33$ \\
\hline Organelle membrane & $1.00 \mathrm{E}-19$ \\
\hline Intracellular organelle part & $2.80 \mathrm{E}-18$ \\
\hline Organelle part & $3.10 \mathrm{E}-18$ \\
\hline Chloroplast thylakoid lumen & $4.00 \mathrm{E}-14$ \\
\hline Thylakoid lumen & $4.00 \mathrm{E}-14$ \\
\hline Plastid thylakoid lumen & $4.00 \mathrm{E}-14$ \\
\hline Plastid stroma & $6.10 \mathrm{E}-13$ \\
\hline Photosynthesis & $1.80 \mathrm{E}-11$ \\
\hline Cellular biosynthetic process & $3.50 \mathrm{E}-11$ \\
\hline Membrane & 8.90E-11 \\
\hline Biosynthetic process & $2.70 \mathrm{E}-08$ \\
\hline Catalytic activity & $6.00 \mathrm{E}-08$ \\
\hline Porphyrin biosynthetic process & $6.10 \mathrm{E}-08$ \\
\hline Tetrapyrrole biosynthetic process & $6.10 \mathrm{E}-08$ \\
\hline Plastoglobule & $2.50 \mathrm{E}-07$ \\
\hline Carboxylic acid metabolic process & $9.20 \mathrm{E}-07$ \\
\hline Metabolic process & $2.20 \mathrm{E}-06$ \\
\hline Tetrapyrrole metabolic process & $2.20 \mathrm{E}-06$ \\
\hline Porphyrin metabolic process & $2.20 \mathrm{E}-06$ \\
\hline Amino acid metabolic process & $3.60 \mathrm{E}-06$ \\
\hline Plastid envelope & $4.00 \mathrm{E}-06$ \\
\hline Chloroplast envelope & $4.10 \mathrm{E}-06$ \\
\hline Chlorophyll biosynthetic process & $4.20 \mathrm{E}-06$ \\
\hline Chloroplast stroma & $8.70 \mathrm{E}-06$ \\
\hline Photosystem & $1.30 \mathrm{E}-05$ \\
\hline Amino acid biosynthetic process & $3.90 \mathrm{E}-05$ \\
\hline Chloroplast inner membrane & 7.70E-05 \\
\hline Nitrogen compound metabolic process & 7.70E-05 \\
\hline Amine metabolic process & $1.10 \mathrm{E}-04$ \\
\hline Plastid inner membrane & $1.20 \mathrm{E}-04$ \\
\hline Pigment biosynthetic process & $1.40 \mathrm{E}-04$ \\
\hline Carbohydrate metabolic process & $1.40 \mathrm{E}-04$ \\
\hline Heterocycle metabolic process & $1.50 \mathrm{E}-04$ \\
\hline Chlorophyll metabolic process & $2.10 \mathrm{E}-04$ \\
\hline Cofactor metabolic process & $2.10 \mathrm{E}-04$ \\
\hline \multirow[t]{2}{*}{ Translation } & $2.10 \mathrm{E}-04$ \\
\hline & n next page) \\
\hline
\end{tabular}


taining the genes Jarl (Staswick et al. 1992) , Pad4 (Glazebrook et al. 1997), Nprl (Cao et al. 1994), Rin4 (Mackey et al. 2002), and several Wrky transcription factor genes, suggesting that tomato homologues of these genes are involved in defense against $C$. fulvum but not against $V$. dahliae. Interestingly, jasmonic acid and salicylic acid responses are over-represented in the compatible $C$. fulvum-tomato interaction, whereas ethylene responses are over-represented in the compatible $V$. dahliaetomato interaction. Water channel activity and ion-binding categories are over-represented in the $V$. dahliae-tomato interaction and not in the C. fulvum-tomato interaction. The most prominent ion-binding category, the manganese ion binding, contains several germin-like proteins (Table 2). Furthermore, categories involved in cytoskeletal and microtubule organization, movement, and transport are overrepresented in the $V$ dahliae-tomato interaction. Finally, the Cajal body category (GO cellular localization) is repressed in the $V$. dahliae-tomato interaction.

Table 2. (continued from preceding page)

\begin{tabular}{ll}
\hline Gene Ontology subcategory & \\
\hline C. fulvum-tomato repressed categories (Continued) & $\boldsymbol{P}$ value \\
Nucleoid & \\
Plastid nucleoid & $2.20 \mathrm{E}-04$ \\
Plastid chromosome & $2.20 \mathrm{E}-04$ \\
tRNA aminoacylation for protein translation & $2.20 \mathrm{E}-04$ \\
Response to light stimulus & $2.60 \mathrm{E}-04$ \\
Amino acid activation & $2.60 \mathrm{E}-04$ \\
tRNA aminoacylation & $2.60 \mathrm{E}-04$ \\
Nitrogen compound biosynthetic process & $2.60 \mathrm{E}-04$ \\
Pigment metabolic process & $3.10 \mathrm{E}-04$ \\
Plastid organization and biogenesis & $3.60 \mathrm{E}-04$ \\
Ligase activity, forming aminoacyl-tRNA and related & $3.60 \mathrm{E}-04$ \\
compounds & $3.70 \mathrm{E}-04$ \\
Ligase activity, forming carbon-oxygen bonds & $3.70 \mathrm{E}-04$ \\
Aminoacyl-tRNA ligase activity & $3.70 \mathrm{E}-04$ \\
Chloroplast membrane & $3.70 \mathrm{E}-04$ \\
Response to radiation & $4.30 \mathrm{E}-04$ \\
Cofactor biosynthetic process & $4.50 \mathrm{E}-04$ \\
Photosystem II & $5.50 \mathrm{E}-04$ \\
Anchored to membrane & $6.60 \mathrm{E}-04$ \\
Amine biosynthetic process & $6.60 \mathrm{E}-04$ \\
Plastid membrane & $7.20 \mathrm{E}-04$ \\
Adenyl nucleotide binding & $9.80 \mathrm{E}-04$ \\
Macromolecule biosynthetic process & $1.70 \mathrm{E}-03$ \\
Amino acid and derivative metabolic process & $2.00 \mathrm{E}-03$ \\
FK506 binding & $2.50 \mathrm{E}-03$ \\
Macrolide binding & $2.50 \mathrm{E}-03$ \\
Generation of precursor metabolites and energy & $2.50 \mathrm{E}-03$ \\
Cellular component & $2.50 \mathrm{E}-03$ \\
Organellar ribosome & $2.50 \mathrm{E}-03$ \\
Plastid ribosome & $2.50 \mathrm{E}-03$ \\
Hydrolase activity, acting on glycosyl bonds & $2.50 \mathrm{E}-03$ \\
Chloroplast organization and biogenesis & $2.50 \mathrm{E}-03$ \\
Unsaturated fatty acid metabolic process & $2.60 \mathrm{E}-03$ \\
Unsaturated fatty acid biosynthetic process & $2.60 \mathrm{E}-03$ \\
Organellar large ribosomal subunit & $2.60 \mathrm{E}-03$ \\
Plastid large ribosomal subunit & $2.60 \mathrm{E}-03$ \\
tRNA metabolic process & $3.10 \mathrm{E}-03$ \\
Structural molecule activity & $3.10 \mathrm{E}-03$ \\
Adenyl ribonucleotide binding & $3.80 \mathrm{E}-03$ \\
Branched chain family amino acid metabolic process & $4.10 \mathrm{E}-03$ \\
Drug binding & $4.10 \mathrm{E}-03$ \\
Aspartate family amino acid biosynthetic process & $5.10 \mathrm{E}-03$ \\
Chloroplast photosystem II & $5.10 \mathrm{E}-03$ \\
Peptidyl-prolyl cis-trans isomerase activity & $7.30 \mathrm{E}-03$ \\
ATP binding & $8.20 \mathrm{E}-03$ \\
Organelle lumen & $8.30 \mathrm{E}-03$ \\
Membrane-enclosed lumen & $8.30 \mathrm{E}-03$ \\
\hline
\end{tabular}

\section{Pathway reconstruction reveals processes} that are inversely regulated by $C$. fulvum and $V$. dahliae.

Pathway reconstruction is a valuable tool to identify cellular processes that might otherwise be obscured by the large amount of primary transcription data. Although this tool is widely used for analysis of human and murine transcriptome data, it has hardly been used to analyze plant transcriptome data (van Baarlen et al. 2008; van Esse et al. 2008). Despite the currently available tools that facilitate cellular pathway reconstruction from plant gene expression data, pathway reconstruction in plants remains a challenge, especially in nonmodel plants such as tomato (van Baarlen et al. 2008). Here, we performed pathway reconstruction on the subset of genes that was regulated by both pathogens in the compatible or incompatible interactions but displayed inverse regulation. This set of 164 and 72 inversely regulated genes between the compatible and incompatible interactions, respectively (Fig. 3), may reveal biological processes that are activated by one pathogen and repressed by the other. The BioNetBuilder plugin (Avila-Campillo et al. 2007), an open-source tool that enables generation of

Table 3. Over-representation analysis of differentially regulated genes in roots during the compatible Verticillium dahliae-tomato interaction

\begin{tabular}{|c|c|}
\hline Gene Ontology subcategory & $P$ value $^{\mathrm{a}}$ \\
\hline \multicolumn{2}{|l|}{ V. dahliae-tomato induced categories } \\
\hline Extracellular region & $2.50 \mathrm{E}-04$ \\
\hline Manganese ion binding & $8.60 \mathrm{E}-04$ \\
\hline Response to ethylene stimulus & $1.10 \mathrm{E}-03$ \\
\hline Cation binding & $1.10 \mathrm{E}-03$ \\
\hline Transition metal ion binding & $1.80 \mathrm{E}-03$ \\
\hline Metal ion binding & $2.00 \mathrm{E}-03$ \\
\hline Ion binding & $2.00 \mathrm{E}-03$ \\
\hline Zinc ion binding & $2.00 \mathrm{E}-03$ \\
\hline $\begin{array}{l}\text { Two-component signal transduction } \\
\text { (phosphorelay) }\end{array}$ & $2.00 \mathrm{E}-03$ \\
\hline Defense response, incompatible interaction & $2.30 \mathrm{E}-03$ \\
\hline Apoplast & $3.30 \mathrm{E}-03$ \\
\hline Response to biotic stimulus & $3.70 \mathrm{E}-03$ \\
\hline Response to fungus & 4.50E-03 \\
\hline Defense response to fungus & $5.70 \mathrm{E}-03$ \\
\hline Protein tyrosine/serine/threonine phosphatase activity & $7.90 \mathrm{E}-03$ \\
\hline Response to endogenous stimulus & $7.90 \mathrm{E}-03$ \\
\hline \multicolumn{2}{|l|}{ V. dahliae-tomato repressed categories } \\
\hline Intracellular nonmembrane-bounded organelle & $5.60 \mathrm{E}-10$ \\
\hline Nonmembrane-bounded organelle & $5.60 \mathrm{E}-10$ \\
\hline Ribonucleoprotein complex & $2.40 \mathrm{E}-05$ \\
\hline Organelle organization and biogenesis & $2.40 \mathrm{E}-05$ \\
\hline Ribosome biogenesis and assembly & $2.70 \mathrm{E}-05$ \\
\hline Microtubule cytoskeleton & $3.30 \mathrm{E}-05$ \\
\hline Cytoskeletal part & $3.40 \mathrm{E}-05$ \\
\hline Macromolecular complex & $3.40 \mathrm{E}-05$ \\
\hline Structural constituent of ribosome & $4.60 \mathrm{E}-05$ \\
\hline Microtubule-based movement & $5.00 \mathrm{E}-05$ \\
\hline Translation & $5.70 \mathrm{E}-05$ \\
\hline Cytoskeleton-dependent intracellular transport & $6.50 \mathrm{E}-05$ \\
\hline Ribonucleoprotein complex biogenesis and assembly & $6.90 \mathrm{E}-05$ \\
\hline Microtubule motor activity & $7.90 \mathrm{E}-05$ \\
\hline Ribosome & $8.50 \mathrm{E}-05$ \\
\hline Cellular component organization and biogenesis & $8.70 \mathrm{E}-05$ \\
\hline Motor activity & $9.70 \mathrm{E}-05$ \\
\hline Cytoskeleton & $1.70 \mathrm{E}-04$ \\
\hline Structural molecule activity & $2.30 \mathrm{E}-04$ \\
\hline Cytoskeleton organization and biogenesis & 8.30E-04 \\
\hline Microtubule-based process & $1.20 \mathrm{E}-03$ \\
\hline Microtubule-associated complex & $1.60 \mathrm{E}-03$ \\
\hline Protein folding & $1.80 \mathrm{E}-03$ \\
\hline rRNA processing & $2.90 \mathrm{E}-03$ \\
\hline rRNA metabolic process & $2.90 \mathrm{E}-03$ \\
\hline Prefoldin complex & 4.40E-03 \\
\hline Cytosolic part & $5.00 \mathrm{E}-03$ \\
\hline Cajal body & $9.10 \mathrm{E}-03$ \\
\hline
\end{tabular}

${ }^{\mathrm{a}}$ False discovery rate. 
biological networks based on integrated information from several databases that include the Biomolecular Interaction Network Database (BIND) (Gilbert 2005), Prolinks (Bowers et al. 2004), and the Kyoto Encyclopedia of Genes and Genomes database (KEGG) (Kanehisa et al. 2002), was used by exploiting the previously identified Arabidopsis RefSeq identifiers. Subsequently, pathways were visualized in Cytoscape as network graphs by representing molecular components (such as proteins) as nodes and intermolecular interactions as links (edges) between nodes (Shannon et al. 2003). A pathway was identified with 14 interacting gene products implicated in photorespiration, hypoxia, and glycoxylate metabolism (Fig. 5A through $\mathrm{C}$ ). We subsequently grafted the expression data of the corresponding genes $(P<0.05)$ onto the identified pathway, showing a differential regulation of this pathway by both pathogens in the compatible interaction (Fig. 5A through $\mathrm{C}$ ) and, similarly, also in the incompatible interaction (data not shown).
Although most components of this pathway are repressed upon C. fulvum inoculation (Fig. 5A), they are induced by $V$. dahliae in roots (Fig. 5B) and even more strongly in the foliage (Fig. 5C). In a similar way, a small interaction cascade with two genes that are involved in auxin signaling was identified. Both genes, AtAux2-11 (Wyatt et al. 1993) and the IAA16 transcription factor gene (Kim et al. 1997), were repressed by C. fulvum and induced by $V$. dahliae. BioNetBuilder allows expansion of gene sets to include neighboring nodes in iterative steps to find new interactions with molecular components identified in the previous step (Avila-Campillo et al. 2007). In this way, after three iterative steps, a predicted network containing 21 proteins was identified based on the two auxin-signaling genes (Fig. 5D through F). For 12 of these 21 proteins, probe sets were present on the tomato GeneChip. Remarkably, nine of those genes were differentially regulated $(P<0.05)$ upon inoculation with least one of the pathogens. Similar to AtAux-11 and
A

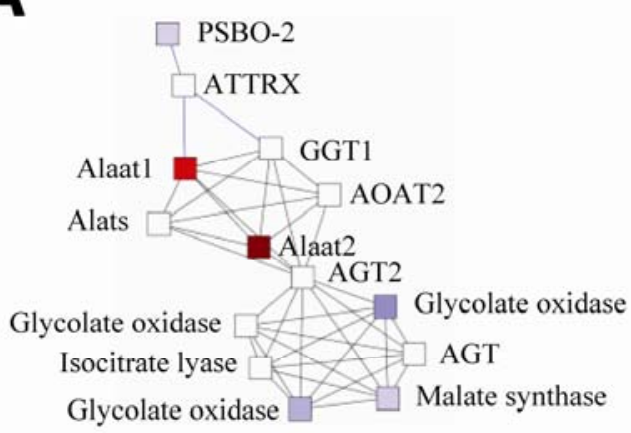

B

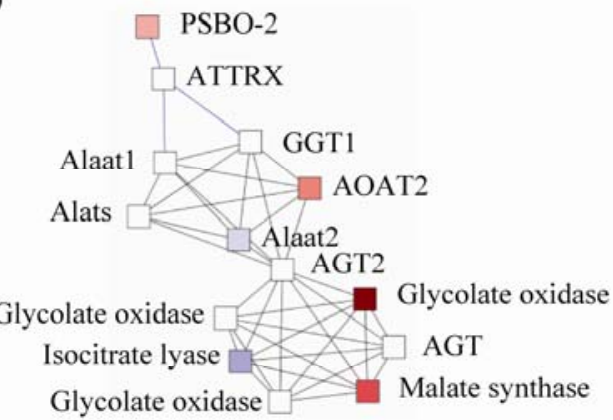

C

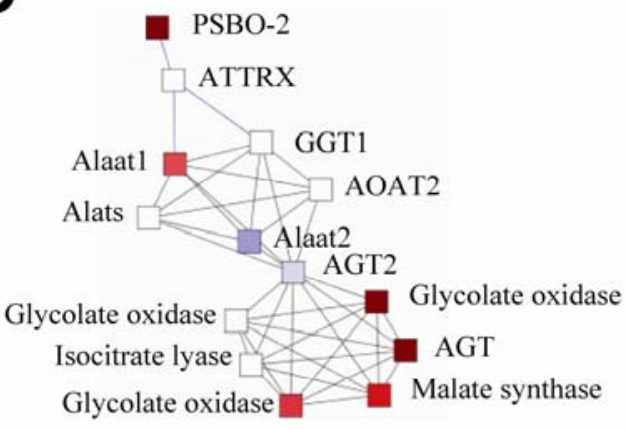

$+3$

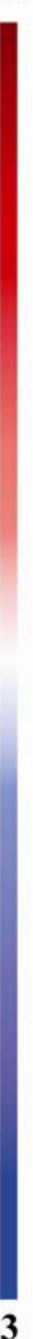

D

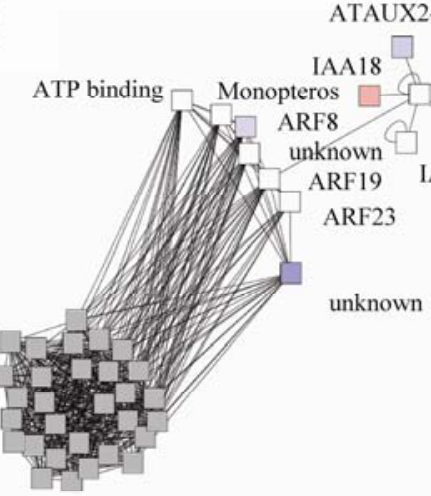

$\mathrm{SHY} 2$
IAA1

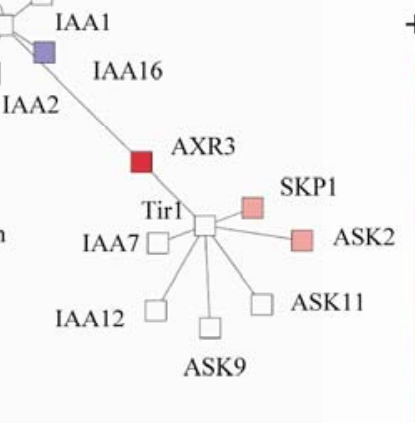

$+3$
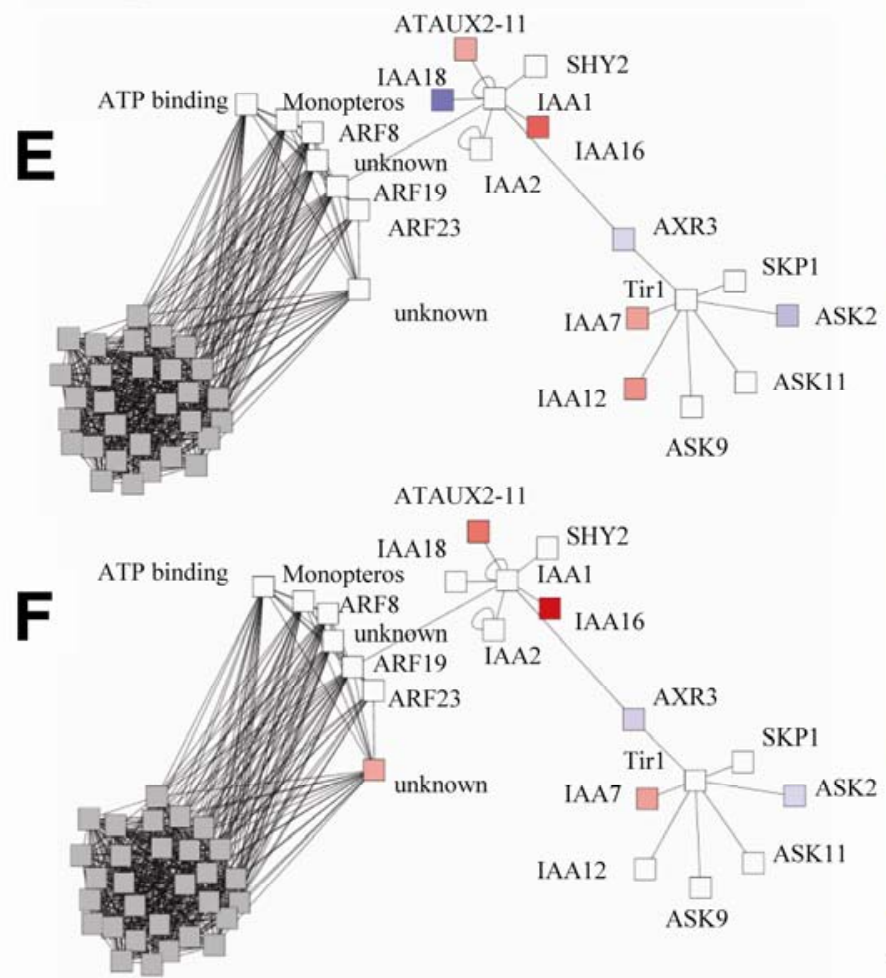

SHY2
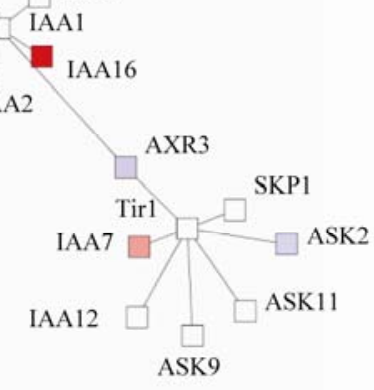

Fig. 5. Pathway reconstruction reveals protein interaction networks. A, B, and C, Responses of susceptible tomato upon inoculation of Cladosporium fulvum were compared with those of tomato inoculated with Verticillium dahliae using the Bionetbuilder plug-in. A protein interaction network implied in both interactions was retrieved and visualized in Cytoscape. Subsequently, expression data monitored with the tomato GeneChip were grafted onto the network. A, Network response upon inoculation with $C$. fulvum. B, Network response in foliar tissues upon inoculation with $V$. dahliae. C, Network response in root tissues upon inoculation with $V$. dahliae. D, E, and F, Small protein interaction network implied in auxin signaling was retrieved. After three iterative steps in the Bionetbuilder, a protein interaction network was obtained that is visualized in Cytoscape. Subsequently, expression data monitored with the tomato GeneChip were grafted onto the network. Gray nodes indicate proteins for which expression was not considered. D, Network response upon inoculation with C. fulvum. E, Network response in foliar tissues upon inoculation with $V$. dahliae. F, Network response in root tissues upon inoculation with $V$. dahliae. 
IAA16, the genes encoding the negative auxin-signaling regulator AXR3 (Leyser et al. 1996) and the Skp1-CUL1-Fbox protein ASK2 (Arabidopsis Skp-1-like 2) (Park et al. 1993) were inversely regulated. Also present in the pathway is the Tir1 (transport inhibitor response) protein, an orthologue of human Skp2, that is able to bind to ASK2 (Ruegger et al. 1998). Interestingly, in addition to Tir1, ASK2 also is known to bind to the negative regulator of jasmonate signaling COI1 (Devoto et al. 2002). The gene encoding AXR3 (Nagpal et al. 2000) was specifically induced in the $V$. dahliae-tomato interaction (Fig. 5D through F). Recently, it has been demonstrated that Arabidopsis mutants in AXR3 display 10-fold reduction of Pseudomonas syringae pv. maculicola colonization (Wang et al. 2007). Finally, the auxin-inducible IAA18 gene (Reed 2001) also was induced by $C$. fulvum and repressed by $V$. dahliae (Fig. 5D through F).

\section{DISCUSSION}

In this study, we used microarrays to monitor global transcriptional responses of tomato upon inoculation with the foliar pathogen $C$. fulvum and the vascular pathogen $V$. dahliae in both a compatible and an incompatible interaction. When examining the response to each of the two pathogens separately, a significant overlap was observed in the response of tomato when comparing the compatible and incompatible interactions. These observations are similar to other transcriptomics studies that compared compatible and incompatible plant-pathogen interactions (Eulgem et al. 2004; Navarro et al. 2004; Tao et al. 2003; Thilmony et al. 2006). For both pathogens, approximately twothirds of the genes that are differentially regulated in the incompatible interaction are also differentially regulated in the compatible interaction (Fig. 2). This complies with the currently held hypothesis that race-specific resistance can largely be seen as an accelerated and amplified basal defense response. Intriguingly, many fewer differentially expressed genes were observed in the interaction with $V$. dahliae than with $C$. fulvum. Possibly, this may be explained by the fact that $C$. fulvum invades living plant tissue, namely the leaf mesophyll, whereas $V$. dahliae resides in the xylem tissues that are actually composed of dead cells. Consequently, direct physical contact of the pathogen with living plant cells that are able to respond is likely to be more extensive in case of $C$. fulvum.

In incompatible interactions, resistance against $C$. fulvum and $V$. dahliae is conveyed by extracellular transmembrane receptors that belong to the class of receptor-like proteins (RLP) (Fradin and Thomma 2006; Thomma et al. 2005; Wang et al. 2008). Resistance against $C$. fulvum is governed by $C f$ genes (Thomma et al. 2005), of which we employed the $C f-9$ gene in this study (Jones et al. 1994) whereas, in all V. dahliae-resistant tomato cultivars, resistance is governed by a single locus that contains two resistance genes, Vel and Ve2 (Kawchuk et al. 2001). Because RLP lack obvious cytoplasmic signaling domains, it has been proposed that they associate with receptorlike kinases (RLK) to relay signals across the plasma membrane (Joosten and de Wit 1999), and different RLP possibly associate with the same RLK to activate a general defense signaling cascade. However, our study suggests that the signaling cascade that is activated by $C f-9$ is different from the cascade that is activated by $V e I$ and $V e 2$, because both pathogens regulate highly divergent gene sets in the incompatible interactions (Fig. 3). Indeed, it was recently shown that the requirement of downstream components for resistance against these two pathogens is largely different (E. F. Fradin and B. P. H. J. Thomma, unpublished results).

$C$. fulvum and V. dahliae display several commonalities in their infection strategies, such as penetration trough natural openings and strictly extracellular growth without the formation of haustoria. Nevertheless, the transcriptional changes induced in tomato by the two pathogens in their compatible interactions hardly overlap. Previously, the transcriptional response of Arabidopsis upon challenge with a host (Erysiphe cichoracearum) and a nonhost (B. graminis f. sp. hordei) powdery mildew isolate revealed that $B$. graminis f. sp. hordei elicited a more dramatic response than E. cichoracearum. It was suggested that plants respond more powerful to $B$. graminis $\mathrm{f}$. sp. hordei because it cannot evade or suppress basal defenses as efficiently as the host powdery mildew, E. cichoracearum (Stein et al. 2006; Zimmerli et al. 2004). Moreover, attackerspecific transcriptomes have also been observed in Arabidopsis upon challenge with different microbial pathogens and feeding insects (de Vos et al. 2005).

Apart from the commonalities in the colonization strategies of $C$. fulvum and $V$. dahliae, there are also obvious differences. The most significant difference is the tissue that is colonized; the leaf apoplast by $C$. fulvum and the xylem by $V$. dahliae. Whereas $C$. fulvum is in close contact with mesophyll cells, $V$. dahliae resides in dead tracheids and may not have direct physical contact with living plant cells. Furthermore, during colonization, $V$. dahliae has been reported to secrete potent phytotoxins into the xylem that are dispersed throughout the plant with the sap stream, whereas $C$. fulvum is not known to utilize toxin activity (Fradin and Thomma 2006; Thomma et al. 2005). Several studies show that the fungus enters the xylem vessels of the root and starts sporulation after 2 to 5 days (Chen et al. 2004; Gold and Robb 1995; Heinz et al. 1998). After 1 week, this sporulation results in colonization of stem vessels, at which time fungal elimination as a consequence of plant defense also occurs. In a compatible interaction, the pathogen is able to overcome this elimination (Chen et al. 2004; Gold and Robb 1995; Heinz et al. 1998). Because $V$. dahliae is a wilt pathogen, the more prominent expression of genes that are associated with water stress and dehydration, such as several $\delta$-TIP aquaporin-like genes, and transporters may be expected. The prominent occurrence of the manganese ion-binding category in the ORA of the compatible $V$. dahliae-tomato interaction in roots is interesting because it concerns four germin-like proteins that may play a role in reinforcement plant cell walls upon pathogen attack (Schweizer et al. 1999; Wei et al. 1998). Therefore, cell wall fortifications may be more important in defense against $V$. dahliae (Fradin and Thomma 2006) when compared with $C$. fulvum. The over-representation of gene categories involved in cytoskeletal and microtubule organization, movement, and transport in the set of $V$. dahliae-repressed genes further supports this observation.

A remarkable difference between the transcriptional changes induced in tomato by both pathogens is the prominent occurrence of WRKY transcription factors in the C. fulvum interaction whereas, in the interaction with $V$. dahliae, these transcription factors are not induced. Upon C. fulvum infection, the tomato homologs of the Arabidopsis WRKY transcription factors $2,3,4,6,7,23,51,53$, and 71 are differentially regulated. Of these, WRKY 4, 6, 7, 51, and 53 have previously been implicated in plant defense and senescence responses (Dong et al. 2003; Eulgem and Somssich 2007; Eulgem et al. 2000; Kalde et al. 2003; Robatzek and Somssich 2001). Furthermore, induction of glutathione S-transferases and serine-type protease inhibitors is specifically observed in the C. fulvum-tomato interaction. Both types of proteins may attenuate the oxidative burst (Lamb and Dixon 1997) that plays a role in tomato defense against $C$. fulvum (Hammond-Kosack et al. 1996). Other genes that are specifically induced by $C$. fulvum in tomato are those that code for NAM-like proteins (Souer et al. 1996) that, together with ATAF and CUP-SHAPED COTYLEDON (CUC), 
are part of a larger NAC (for NAM, ATAF, and CUC) protein family of transcription factors (Aida et al. 1997). Some $N A C$ genes, such as the ATAF1 and ATAF2 genes from Arabidopsis and the StNAC gene from potato, are induced by pathogen attack and wounding (Aida et al. 1997; Collinge and Boller 2001). Furthermore, many NAC genes were differentially regulated in the interaction between the nematode Heterodera glycines and soybean (Klink et al. 2007). Recently, the barley NAC gene HvNAC6 was implicated in basal defense against the barley powdery mildew pathogen Botrytis graminis f. sp. hordei (Jensen et al. 2007). Furthermore, Arabidopsis ATAF2 is known to repress $P R$ genes, and ATAF2-overexpressing plants showed a higher susceptibility to the soilborne vascular fungal pathogen Fusarium oxysporum (Delessert et al. 2005). Other Arabidopsis NAC members are involved in secondary cell wall thickening (Mitsuda et al. 2005; Zhong and Ye 2007) and in auxin and ethylene signaling (Guo et al. 2005; He et al. 2005). Also, in a cDNA amplified fragment length polymorphism analysis on tomato transgenes that undergo a controlled hypersensitive response due to heterologous expression of $C$. fulvum Avr4 in $C f-4$ plants, transcripts for NAM-like proteins and a WRKY transcription factor were identified (Gabriëls et al. 2006). The activation of different defense cascades is also visible in the ORA of the compatible interactions with C. fulvum and V. dahliae with over-represented gene categories such as jasmonic acid and salicylic acid responses, as well as expression of tomato homologues Jarl (Staswick et al. 1992), Pad4 (Glazebrook et al. 1997), Nprl (Cao et al. 1994), and Rin4 (Mackey et al. 2002) by $C$. fulvum but not by $V$. dahliae.

A surprising observation is the inverse regulation of photosynthesis in tomato upon challenge by C. fulvum and V. dahliae. Strong repression of photosynthesis, as in $C$. fulvum-challenged tomato, is a typical plant response to pathogen attack (Berger et al. 2007; Dowd et al. 2004; Scheideler et al. 2002; Zimmerli et al. 2004). However, local stimulation of photosynthesis has been noted, too, because Albugo candida infection of Arabidopsis and Botrytis cinerea infection of tomato results in decreased photosynthesis at the infection site, surrounded by a zone of enhanced photosynthesis (Berger et al. 2004; Chou et al. 2000). In a recent study, transcription profiles were determined for stem tissue of Craigella tomato plants infected with two different $V$. dahliae isolates using a cDNA array to interrogate expression of approximately 8,600 tomato genes (Robb et al. 2007). Infection with isolate Vd1 resulted in a compatible interaction while infection with isolate E6 resulted in a tolerant interaction. Also in this study, as with our findings, stimulation of photosynthesis by $V$. dahliae was observed in both the tolerant and compatible interaction (Robb et al. 2007). Moreover, Robb and associates (2007) noted induction of a gene encoding a 14-3-3 protein in the compatible interaction with $V$. dahliae, whereas this gene was repressed in a tolerant tomato genotype that develops few symptoms despite substantial fungal colonization, suggesting that this gene may be elementary for the tolerance phenotype. However, in a tolerant cotton genotype, a gene encoding a 14-3-3 protein was found to be activated upon $V$. dahliae challenge (Hill et al. 1999). In our study, genes encoding 14-3-3 proteins were found to be induced in both the compatible and incompatible interactions with $V$. dahliae in leaves and roots but also in the interactions with $C$. fulvum.

Few microarray studies have been performed to monitor the transcriptional changes of different plant tissues upon pathogen infection. One example is the profiling in cotton roots and hypocotyls in response to infection with $F$. oxysporum (Dowd et al. 2004). Also, in this study, it appeared that tissues responded quite differently to infection. Substantially more induced plant genes were identified in infected cotton hypocotyl tissues than in root tissues, suggesting that the fungus may be suppressing plant defense responses in the root tissue (Dowd et al. 2004). Also, our transcriptional profiling of roots and foliage of $V$. dahliae-infected tomato in the compatible interaction revealed significant differences in expression profiles between the two tissues. In contrast to the $F$. oxysporum-infected cotton, in our study, more genes were induced in the roots than in the foliage.

With pathway reconstruction, it was attempted to uncover additional differentially regulated biological processes in the global transcription profiles. Although it has become accepted presently that, with careful experiment design and rigorous statistical analysis, confirmation of expression data by using an alternative technique is not necessary for high-quality, commercially available array platforms (Wise et al. 2007), the identification of differentially regulated biological processes further substantiates the results obtained by the transcriptional profiling. Among the gene sets inversely regulated by the two pathogens is a pathway that can be implicated in photorespiration, hypoxia, and glycoxylate metabolism. It has previously been shown that these processes are repressed upon pathogen attack (Berger et al. 2007; Scheideler et al. 2002; Zimmerli et al. 2004). Glutamate:glyoxylate aminotransferase (GGT1) is a peroxisomal enzyme that plays a central role in the photorespiratory pathway (Liepman and Olsen 2003). Peroxisomal alanine:glyoxylate aminotransferases AGT1 and AGT2 and alanine:2-oxoglutarate aminotransferase AOAT2 have also been implicated in photorespiration, although the exact metabolic function of AGT2 and AOAT2 remain unclear (Igarashi et al. 2003; Liepman and Olsen 2003). ALaAT1 and ALaAT2 have recently been shown to be induced by oxygen deprivation (Miyashita et al. 2007). Interestingly, malate synthase is induced during the $V$. dahliaetomato interaction and repressed during the C. fulvum-tomato interaction. Malate syntase is part of the glyoxylate cycle and expression of this gene is repressed when sucrose is being synthesized (e.g., in photosynthetic tissues), although induction has also been observed in senescent organs (Graham et al. 1992). Interestingly, it has been noted previously that $V$. dahliae induces early senescence in several host plants (du Toit et al. 2005; Joaquim and Rowe 1991; Sadras et al. 2000; Veronese et al. 2003). Peroxisomal glycolate oxidases have a clear role in plant defense and programmed cell death (Grant and Loake 2000; Hammond-Kosack and Jones 1996) but also play a role in photoresperation (Fukao et al. 2002). Another gene in the pathway, PSBO-2, is part of the photosystem II and clearly links this pathway to the differential regulation of photosynthetic genes. Altogether, this pathway analysis shows that, apart from photosynthesis, the photorespiratory system of tomato also is differentially regulated upon infection by the two pathogens.

A similar situation as for the photorespiratory system occurs for an auxin-signaling pathway. Previously, auxin signaling has been implicated in the response of cotton to $F$. oxysporum infection (Dowd et al. 2004). With respect to the role of auxin in plant defenses, it has been shown that an Arabidopsis miRNA contributes to resistance against $P$. syringae by repressing auxin signaling (Navarro et al. 2006), and salicylic acid was found to inhibit the growth of pathogens via repression of the auxin-signaling pathway (Wang et al. 2007). Recently, the $P$. syringae type III effector AvrRpt2 was found to alter auxin physiology in Arabidopsis (Chen et al. 2007), suggesting that modulation of auxin signaling contributes to host susceptibility. Furthermore, some strains of the bacterial pathogen Ralstonia solanacearum are known to produce auxin, the production of which is controlled by an hrp master regulatory gene whose activity is induced the in presence of plant cells (Valls et al. 2006). Finally, auxin produced by $P$. syringae pv. savastanoi appears to be required for the inhibition of plant defenses (Robinette and Matthysse 1990). 
Overall, it can be concluded that global transcriptional profiling of tomato during compatible and incompatible interactions with the foliar pathogenic fungus $C$. fulvum and the vascular pathogenic fungus $V$. dahliae revealed only limited overlap. Furthermore, with novel strategies that allowed the use of stateof-the-art tools, differentially regulated pathways were identified that provide new insight into pathogen biology even though tomato is not a genetic model organism.

\section{MATERIALS AND METHODS}

\section{Cultivation of microorganisms and plant inoculations.}

$C$. fulvum and $V$. dahliae were cultured at room temperature on half-strength potato dextrose broth (Oxoid, Basingstoke, England) supplemented with technical agar at $7 \mathrm{~g} /$ liter (Oxoid). All tomato plants were grown in soil under standard greenhouse conditions: 21 and $19^{\circ} \mathrm{C}$ during day and night periods of 16 and $8 \mathrm{~h}$, respectively; $70 \%$ relative humidity (RH); and supplemental light of $100 \mathrm{~W} / \mathrm{m}^{2}$ when the intensity dropped below $150 \mathrm{~W} / \mathrm{m}^{2}$. For inoculations of tomato with $C$. fulvum, $5 \mathrm{ml}$ of conidial suspension $\left(1 \times 10^{6}\right.$ conidia/$\mathrm{ml}$ ) was sprayed on the lower surface of leaves of 5-week-old tomato plants (van Esse et al. 2007). Plants were kept at high $\mathrm{RH}$ under a plastic cover for $48 \mathrm{~h}$ after inoculation. For inoculation with $V$. dahliae, 10-day-old soil-grown tomato plants were uprooted and inoculated by dipping the roots for 2 min in a conidial suspension $\left(10^{6}\right.$ conidia $\left./ \mathrm{ml}\right)$ in water. After replanting in soil, plants were incubated at standard greenhouse conditions of 16- and 8-h light and dark regime, respectively, and $70 \% \mathrm{RH}$.

\section{Microarray sample preparation and data analyses.}

All samples were collected in three independently repeated experiments. A race 5 strain of $C$. fulvum $(5 \mathrm{Kim})$ was used for inoculation. MoneyMaker $C f$ - $O$ was used as a $C$. fulvumsusceptible genotype because it is devoid of functional $C f$ resistance genes, while the isogenic MoneyMaker $C f-9$ line was used as a resistant genotype because it recognizes the Avr9 elicitor that is produced by the race $5 C$. fulvum strain. At $0,3,7$, and 10 DPI, leaf material was harvested from the secondary and tertiary leaves of three plants, pooled, and flash frozen in liquid nitrogen. Material harvested at 0 DPI was used as the reference sample to which all other samples were compared.

For $V$. dahliae, a race 1 strain (St14.01) was used for inoculation on MoneyMaker and Motelle tomato plants. MoneyMaker was used as a susceptible genotype because it lacks Verticillium resistance, while Motelle contains the Ve locus that provides resistance against race 1 Verticillium strains (Schaible et al. 1951). At 3 and 7 DPI, foliar and root material was harvested from nine plants, pooled, and flash frozen in liquid nitrogen. As the reference sample to which all other samples were compared, foliar and root material of mock-inoculated plants at 3 DPI was used.

For RNA extraction, the frozen plant material was ground using a mortar and pestle, and approximately $100 \mathrm{mg}$ of the material was homogenized in Trizol reagent (Invitrogen, Carlsbad, CA, U.S.A.). After phase separation, isopropanol was added to the aqueous phase, which was subsequently further purified with the NucleoSpin RNA plant kit (Macherey-Nagel $\mathrm{GmbH}$, Düren, Germany). In this way, total RNA was obtained that was hybridized onto custom-designed Affymetrix tomato GeneChip array (Syngenta Biotechnology, Inc., Research Triangle Park, NC, U.S.A.) that contains probe sets to interrogate 22,721 tomato transcripts (van Esse et al. 2007). Probe preparations and GeneChip hybridizations were carried out at ServiceXS (Leiden, The Netherlands).

\section{Microarray data analyses.}

Bioconductor packages (Gentleman et al. 2004) were used to analyze the scanned Affymetrix arrays. The Bioconductor packages were integrated in the automated online MADMAX pipeline. The arrays were normalized using quantile normalization and expression estimates were compiled using RMA applying the empirical Bayes approach (Wu et al. 2004). They were considered of sufficiently high quality if they showed less than $10 \%$ of specks in fitPLM model images, were not deviating in RNA degradation and density plots, were not significantly deviating in NUSE and RLE plots, and were within each other's range in boxplots. Differentially expressed probesets were identified using linear models, applying moderated $t$ statistics that implement empirical Bayes regularization of standard errors (Smyth 2004). Venn diagrams and basic comparisons were performed in Microsoft Excel. HCL and KMeans clustering were performed using the TM4 microarray software suite and data were imported as Tab Delimited, Multiple Sample Files (TDMS) (**). The TM4 software suite runs in a Java environment (Sun Microsystems, Inc. Santa Clara, CA, U.S.A.).

\section{Microarray data.}

Microarray data have been deposited in ArrayExpress as accession E-MEXP-1844.

\section{ACKNOWLEDGMENTS}

B. P. H. J. Thomma is supported by a Vidi grant of the Research Council for Earth and Life sciences (ALW) of the Netherlands Organization for Scientific Research (NWO). This project was financially supported by the Centre for BioSystems Genomics (CBSG), which is part of the Netherlands Genomics Initiative/NWO and by European Research Area Networks Plant Genomics. We thank Syngenta Biotechnology, Inc. (Research Triangle Park, NC, U.S.A.) for making the custom-designed Affymetrix tomato GeneChip array available; B. Essenstam, T. van den Brink, and H. Smid at Unifarm for excellent plant care; B. Lievens for providing the $V$. dahliae strain; and M. Bolton for critically reading the manuscript.

\section{LITERATURE CITED}

Adams-Phillips, L., Wan, J., Tan, X., Dunning, F. M., Meyers, B. C. Michelmore, R. W., and Bent, A. F. 2008. Discovery of ADP-ribosylation and other plant defense-pathway elements through expression profiling of four different Arabidopsis-Pseudomonas R/avr interactions. Mol. Plant-Microbe Interact. 21:646-657.

Aida, M., Ishida, T., Fukaki, H., Fujisawa, H., and Tasaka, M. 1997. Genes involved in organ separation in Arabidopsis: An analysis of the cupshaped cotyledon mutant. Plant Cell 9:841-857.

Avila-Campillo, I., Drew, K., Lin, J., Reiss, D. J., and Bonneau, R. 2007. BioNetBuilder: Automatic integration of biological networks. Bioinformatics 23:392-393.

Backes, C., Keller, A., Kuentzer, J., Kneissl, B., Comtesse, N., Elnakady, Y. A., Müller, R., Meese, E., and Lenhof, H. P. 2007. GeneTrail-advanced gene set enrichment analysis. Nucleic Acids Res. 35:W186W192.

Berger, S., Papadopoulos, M., Schreiber, U., Kaiser, W., and Roitsch T. 2004. Complex regulation of gene expression, photosynthesis and sugar levels by pathogen infection in tomato. Physiol. Plant. 122:419-428.

Berger, S., Sinha, A. K., and Roitsch, T. 2007. Plant physiology meets phytopathology: Plant primary metabolism and plant-pathogen interactions. J. Exp. Bot. 58:4019-4026.

Bolton, M. D., Kolmer, J. A., Xu, W. W., and Garvin, D. F. 2008a. Lr34mediated leaf rust resistance in wheat: Transcript profiling reveals a high energetic demand supported by transient recruitment of multiple metabolic pathways. Mol. Plant-Microbe Interact.

Bolton, M. D., Esse, H. P., Vossen, J. H., de Jonge, R., Stergiopoulos, I., Stulemeijer, I. J. E., van den Berg, G., Borrás-Hidalgo, O., Dekker, H. L., de Koster, C. G., de Wit, P. J. G. M., Joosten, M. H. A. J., and Thomma, B. P. H. J. 2008b. The novel Cladosporium fulvum lysin motif effector Ecp6 is a virulence factor with orthologs in other fungal species. Mol. Microbiol. 69:119-136.

Bowers, P. M., Pellegrini, M., Thompson, M. J., Fierro, J., Yeates, T. O., 
and Eisenberg, D. 2004. Prolinks: A database of protein functional linkages derived from coevolution. Genome Biol. 5:R35.

Caldo, R. A., Nettleton, D., and Wise, R. P. 2004. Interaction-dependent gene expression in Mla-specified response to barley powdery mildew. Plant Cell 16:2514-2528.

Cao, H., Bowling, S. A., Gordon, A. S., and Dong, X. 1994. Characterization of an Arabidopsis mutant that is nonresponsive to inducers of systemic acquired resistance. Plant Cell 6:1583-1592.

Chen, P., Lee, B., and Robb, J. 2004. Tolerance to a non-host isolate of Verticillium dahliae in tomato. Physiol. Mol. Plant Pathol. 64:283-291.

Chen, Z., Agnew, J. L., Cohen, J. D., He, P., Shan, L., Sheen, J., and Kunkel, B. N. 2007. Pseudomonas syringae type III effector AvrRpt2 alters Arabidopsis thaliana auxin physiology. Proc. Natl. Acad. Sci. U.S.A. 104:20131-20136.

Chou, H. M., Bundock, N. J., Rolfe, S. A., and Scholes, J. D. 2000. Infection of Arabidopsis thaliana leaves with Albugo candida (white blister rust) causes a reprogramming of host metabolism. Mol. Plant Pathol. 1:99-113.

Collinge, M., and Boller, T. 2001. Differential induction of two potato genes, Stprx2 and StNAC, in response to infection by Phytophthora infestans and to wounding. Plant Mol. Biol. 46:521-529.

Daniels, M. J., Mirkov, T. E., and Chrispeels, M. J. 1994. The plasma membrane of Arabidopsis thaliana contains a mercury-insensitive aquaporin that is a homolog of the tonoplast water channel protein TIP. Plant Physiol. 106:1325-1333.

Daniels, M. J., Chaumont, F., Mirkov, T. E., and Chrispeels, M. J. 1996. Characterization of a new vacuolar membrane aquaporin sensitive to mercury at a unique site. Plant Cell 8:587-599.

Daram, P., Brunner, S., Persson, B. L., Amrhein, N., and Bucher, M. 1998. Functional analysis and cell-specific expression of a phosphate transporter from tomato. Planta 206:225-233.

Delessert, C., Kazan, K., Wilson, I. W., Van Der Straeten, D., Manners, J., Dennis, E. S., and Dolferus, R. 2005. The transcription factor ATAF2 represses the expression of pathogenesis-related genes in Arabidopsis. Plant J. 43:745-757.

de Vos, M., van Oosten, V. R., van Poecke, R. M. P., van Pelt, J. A., Pozo, M. J., Mueller, M. J., Buchala, A. J., Métraux, J. P., van Loon, L. C., Dicke, M., and Pieterse, C. M. J. 2005. Signal signature and transcriptome changes of Arabidopsis during pathogen and insect attack. Mol. Plant-Microbe Interact. 18:923-937.

Devoto, A., Nieto-Rostro, M., Xie, D., Ellis, C., Harmston, R., Patrick, E. Davis, J., Sherratt, L., Coleman, M., and Turner, J.G. 2002. COI1 links jasmonate signalling and fertility to the SCF ubiquitin-ligase complex in Arabidopsis. Plant J. 32:457-466.

Dong, J. X., Chen, C. H., and Chen, Z. X. 2003. Expression profiles of the Arabidopsis WRKY gene superfamily during plant defense response. Plant Mol. Biol.51:21-37.

Dowd, C., Wilson, I. W., and McFadden, H. 2004. Gene expression profile changes in cotton root and hypocotyl tissues in response to infection with Fusarium oxysporum f. sp. vasinfectum Mol. Plant-Microbe Interact. 17:654-667.

du Toit, L. J., Derie, M. L., and Hernandez-Perez, P. 2005. Verticillium wilt in spinach seed production. Plant Dis. 89:4-11.

Eckhardt, U., Mas Marques, M. A., and Buckhout, T. J. 2001. Two ironregulated cation transporters from tomato complement metal uptake-deficient yeast mutants. Plant Mol. Biol. 45:437-448.

Eisen, M. B., Spellman, P. T., Brown, P. O., and Botstein, D. 1998. Cluster analysis and display of genome-wide expression patterns. Proc. Natl. Acad. Sci. U.S.A. 95:14863-14868

Eulgem, T., and Somssich, I. E. 2007. Networks of WRKY transcription factors in defense signaling. Curr. Opin. Plant Biol. 10:366-371.

Eulgem, T., Rushton, P. J., Robatzek, S., and Somssich, I. E. 2000. The WRKY superfamily of plant transcription factors. Trends Plant Sci. 5:199-206.

Eulgem, T., Weigman, V. J, Chang, H. S., McDowell, J. M., Holub, E. B., Glazebrook, J., Zhu, T., and Dangl, J. L. 2004. Gene expression signatures from three genetically separable resistance gene signaling pathways for downy mildew resistance. Plant Physiol. 135:1129-1144.

Fradin, E. F., and Thomma, B. P. H. J. 2006. Physiology and molecular aspects of Verticillium wilt diseases caused by $V$. dahliae and V. alboatrum. Mol. Plant. Pathol. 7:71-86.

Fukao, Y., Hayashi, M., and Nishimura, M. 2002. Proteomic analysis of leaf peroxisomal proteins in greening cotyledons of Arabidopsis thaliana. Plant Cell Physiol. 7:689-696.

Gabriëls, S. H. E. J., Takken, F. L. W., Vossen, J. H., de Jong, C. F., Liu, Q., Turk, S. C. H. J., Wachowski, L. K., Peters, J., Witsenboer, H. M. A., de Wit, P. J. G. M., and Joosten, M. H. A. J. 2006. cDNA-AFLP combined with functional analysis reveals novel genes involved in the hypersensitive response. Mol. Plant-Microbe Interact. 19:567-576.

Gilbert, D. 2005. Biomolecular interaction network database. Brief Bioinf. 6:194-198.
Glazebrook, J., Zook, M., Mert, F., Kagan, I., Rogers, E. E., Crute, I. R. Holub, E. B., Hammerschmidt, R., and Ausubel, F. M. 1997. Phytoalexin-deficient mutants of Arabidopsis reveal that PAD4 encodes a regulatory factor and that four PAD genes contribute to downy mildew resistance. Genetics 146:381-392.

Gold, J., and Robb, J. 1995. the role of the coating response in Craigella tomatoes infected with Verticillium dahliae, races 1 and 2. Physiol. Mol. Plant Pathol. 47:141-157.

Graham, I. A., Leaver, C. J., and Smith, S. M. 1992. Induction of malate synthase gene expression in senescent and detached organs of cucumber. Plant Cell 4:349-357.

Guo, H. S., Xie, Q., Fei, J. F., and Chua, N. H. 2005. MicroRNA directs mRNA cleavage of the transcription factor NAC1 to downregulate auxin signals for Arabidopsis lateral root development. Plant Cell 17:13761386.

Guo, Z., Lamb, C., and Dixon, R. A. 1998. Potentiation of the oxidative burst and isoflavonoid phytoalexin accumulation by serine protease inhibitors. Plant Physiol. 118:1487-1494.

Grant, J. J., and Loake, G. J. 2000. Role of reactive oxygen intermediates and cognate redox signaling in disease resistance. Plant Physiol. 124:21-29.

Hammond-Kosack, K. E., and Jones, J. D. G. 1996. Resistance gene-dependent plant defense responses. Plant Cell 8:1773-1791.

Hammond-Kosack, K. E., Silverman, P., Raskin, I., and Jones, J. D. G. 1996. Race-specific elicitors of Cladosporium fulvum induce changes in cell morphology and the synthesis of ethylene and salicylic acid in tomato plants carrying the corresponding $C f$ disease resistance gene. Plant Physiol. 110:1381-1394.

He, X. J., Mu, R. L., Cao, W. H., Zhang, Z. G., Zhang, J. S., and Chen, S. Y. 2005. At-NAC2, a transcription factor downstream of ethylene and auxin signaling pathways, is involved in salt stress response and lateral root development. Plant J. 44:903-916.

Heinz, R., Lee, S.W., Saparno, A., Nazar, R. N., and Robb, J. 1998. Cyclical systemic colonization in Verticillium-infected tomato. Physiol. Mol. Plant. Pathol. 52:385-396.

Hill, M. K., Lyon, K. J., and Lyon, B. R. 1999. Identification of disease response genes expressed in Gossypium hirsutum upon infection with the wilt pathogen Verticillium dahliae. Plant Mol. Biol. 40:289-296.

Igarashi, D., Miwa, T., Seki, M., Kobayashi, M., Kato, T., Tabata, S., Shinozaki, K., and Ohsumi, C. 2003. Identification of photorespiratory glutamate:glyoxylate aminotransferase (GGAT) gene in Arabidopsis. Plant J. 33:975-987.

Jensen, M. K., Rung, J. H., Gregersen, P. L., Gjetting, T., Fuglsang, A. T., Hansen, M., Joehnk, N., Lyngkjaer, M. F., and Collinge, D. B. 2007 The $H v$ NAC6 transcription factor: A positive regulator of penetration resistance in barley and Arabidopsis. Plant Mol. Biol. 65:137-150.

Joaquim, T. R., and Rowe, R. C. 1991. Vegetative compatibility and virulence of strains of Verticillium dahliae from soil and potato plants. Phytopathology 81:552-558.

Jones, D. A., Thomas, C. M., Hammond-Kosack, K. E., Balint-Kurti, P. J., and Jones, J. D. G. 1994. Isolation of the tomato $C f-9$ gene for resistance to Cladosporium fulvum by transposon tagging. Science 266:789-793.

Joosten, M. H. A. J., and de Wit, P. J. G. M. 1999. The tomato-Cladosporium fulvum interaction: A versatile experimental system to study plantpathogen interactions. Annu. Rev. Phytopathol. 37:335-367.

Kalde, M., Barth, M., Somssich, I. E., and Lippok, B. 2003. Members of the Arabidopsis WRKY group III transcription factors are part of different plant defense signaling pathways. Mol. Plant-Microbe Interact. 16:295-305.

Kanehisa, M., Goto, S., Kawashima, S., and Nakaya, A. 2002. The KEGG databases at GenomeNet. Nucleic Acids Res. 30:42-46.

Kawchuk, L., Hachey, J., Lynch, D. R., Klcsar, F., van Rooijen, G., Waterer, D. R., Robertson, A., Kokko, E., Byers, R., Howard, R. J., Fischer, R. and Prüfer, D. 2001. Tomato Ve disease resistance genes encode cell surface-like receptors. Proc. Natl. Acad. Sci. U.S.A. 98:6511-6515.

Kim, J., Harter, K., and Theologis, A. 1997. Protein-protein interactions among the Aux/IAA proteins. Proc. Natl. Acad. Sci. U.S.A. 94:1178611791.

Kjellbom, P., Larsson, C., Johansson, I., Karlsson, M., and Johanson, U. 1999. Aquaporins and water homeostasis in plants. Trends Plant Sci. 4:308-314

Klink, V. P., Overall, C. C., Alkharouf, N. W., MacDonald, M. H., and Matthews, B. F. 2007. A time-course comparative microarray analysis of an incompatible and compatible response by Glycine max (soybean) to Heterodera glycines (soybean cyst nematode) infection. Planta 226:1423-1447.

Kobayashi, S. D., Braughton, K. R., Whitney, A. R., Voyich, J. M., Schwan, T. G., Musser, J. M., and DeLeo, F. R. 2003. Bacterial pathogens modulate an apoptosis differentiation program in human neutrophils. Proc. Natl. Acad. Sci. U.S.A. 100:10948-10953. 
Kronenberger, J., Lepingle, A., Caboche, M., and Vaucharet, H. 1993. Cloning and expression of distinct nitrite reductases in tobacco leaves and roots. Mol. Gen. Genet. 236:203-208.

Krüger, J., Thomas, C. M., Golstein, C., Dixon, M. S., Smoker, M., Tang, S. K., Mulder, L., and Jones, J. D. G. 2002. A tomato cysteine protease required for $\mathrm{Cf}$-2-dependent disease resistance and suppression of autonecrosis. Science 296:744-747.

Lamb, C., and Dixon, R. A. 1997. The oxidative burst in plant disease resistance. Annu. Rev. Plant Physiol. Plant Mol. Biol. 48:251-275.

Leyser, H. M. O., Pickett, F. B., Dharmasiri, S., and Estelle, M. 1996. Mutations in the AXR3 gene of Arabidopsis result in altered auxin response including ectopic expression from the SAUR-AC1 promoter. Plant J. 10:403-413.

Liepman, A. H., and Olsen, L. J. 2003. Alanine aminotransferase homologs catalyze the glutamate:glyoxylate aminotransferase reaction in peroxisomes of Arabidopsis. Plant Physiol. 131:215-227.

Liu, J., Ishitani, M., Halfter, U., Kim, C., and Zhu, J. 2000. The Arabidopsis thaliana SOS2 gene encodes a protein kinase that is required for salt tolerance. Proc. Natl. Acad. Sci. U.S.A. 97:3730-3734.

Mackey, D., Holt, B. F., III., Wiig, A., and Dangl, J. L. 2002. RIN4 interacts with Pseudomonas syringae type III effector molecules and is required for RPM1-mediated resistance in Arabidopsis. Cell 108:743754

Maleck, K., Levine, A., Eulgem, T., Morgan, A., Schmid, J., Lawton, K. A., Dangl, J. L., and Dietrich, R. A. 2000. The transcriptome of Arabidopsis thaliana during systemic acquired resistance. Nat. Genet. 26:403-410

Mitsuda, N., Seki, M., Shinozaki, K., and Ohme-Takagi, M. 2005. The NAC transcription factors NST1 and NST2 of Arabidopsis regulate secondary wall thickenings and are required for anther dehiscence. Plant Cell 17:2993-3006.

Miyashita, Y., Dolferus, R., Ismond, K. P., and Good, A. G. 2007. Alanine aminotransferase catalyses the breakdown of alanine after hypoxia in Arabidopsis thaliana. Plant J. 49:1108-1121.

Nagaoka, S., and Takano, T. 2003. Salt tolerance-related protein STO binds to a Myb transcription factor homologue and confers salt tolerance in Arabidopsis. J. Exp. Bot. 54:2231-2237.

Nagpal, P., Walker, L. M., Young, J. C., Sonawala, A., Timpte, C., Estelle, M., and Reed, J. W. 2000. AXR2 encodes a member of the Aux/IAA protein family. Plant Physiol. 123:563-574.

Navarro, L., Zipfel, C., Rowland, O., Keller, I., Robatzek, S., Boller, T., and Jones, J. D. G. 2004. The transcriptional innate immune response to flg22. Interplay and overlap with Avr gene-dependent defense responses and bacterial pathogenesis. Plant Physiol. 135:1113-1128.

Navarro, L., Dunoyer, P., Jay, F., Arnold, B., Dharmasiri, N., Estelle, M., Voinnet, O., and Jones, J. D. G. 2006. A plant miRNA contributes to antibacterial resistance by repressing auxin signaling. Science 312:436439

Park, Y. S., Hong, S. W., Oh, S. A., Kwak, J. M., Lee, H. H., and Nam, H. G. 1993. Putative protein-kinases from Arabidopsis thaliana contain highly acidic domains. Plant Mol. Biol. 22:615-624.

Pruitt, K. D., Tatusova, T., and Maglott, D. R. 2005. NCBI Reference Sequence (RefSeq): A curated non-redundant sequence database of genomes, transcripts and proteins. Nucleic Acids Res. 33:D501-D504.

Quirino, B. F., and Bent, A. F. 2003. Deciphering host resistance and pathogen virulence: The Arabidopsis/Pseudomonas interaction as a model. Mol. Plant Pathol. 4:517-530.

Reed, J. W. 2001. Roles and activities of Aux/IAA proteins in Arabidopsis. Trends Plant Sci. 6:420-425.

Mass spectrometric identification of isoforms of PR proteins in xylem sap of fungus infected tomato. Plant Physiol. 130:904-917.

Robatzek, S., and Somssich, I. E. 2001. A new member of the Arabidopsis WRKY transcription factor family, AtWRKY6, is associated with both senescence- and defence-related processes. Plant J. 28:123-133.

Robb, J., Lee, B., and Nazar, R. N. 2007. Gene suppression in a tolerant tomato-vascular pathogen interaction. Planta 226:299-309.

Robinette D., and Matthysse, A. G. 1990. Inhibition by Agrobacterium tumefaciens and Pseudomonas savastanoi of development of the hypersensitive response elicited by Pseudomonas syringae pv. phaseolicola. J. Bacteriol. 172:5742-5749.

Ruegger, M., Dewey, E., Gray, W. M., Hobbie, L., Turner, J., and Estelle, M. 1998. The TIR1 protein of Arabidopsis functions in auxin response and is related to human SKP2 and yeast Grrlp. Genet. Dev. 12:198207

Sadras, V. O., Quiroz, F., Echarte, L., Escande, A., and Pereyra, V. R. 2000. Effect of Verticillium dahliae on photosynthesis, leaf expansion and senescence of field-grown sunflower. Ann. Bot. 86:1007-1015.

Scheideler, M., Schlaich, N. L., Fellenberg, K., Beissbarth, T., Hauser, N. C., Vingron, M., Slusarenko, A. J., and Hoheisel, J. D. 2002. Monitoring the switch from housekeeping to pathogen defense metabolism in
Arabidopsis thaliana using cDNA arrays. J. Biol. Chem. 277:1055510561.

Schenk, P. M., Kazan, K., Wilson, I., Anderson, J. P., Richmond, T., Somerville, S. C., and Manners, J. M. 2000. Coordinated plant defense responses in Arabidopsis revealed by microarray analysis. Proc. Natl. Acad. Sci. U.S.A. 97:11655-11660.

Scholz-Starke, J., Büttner, M., and Sauer, N. 2003. AtSTP6, a new pollenspecific $\mathrm{H}^{+}$-monosaccharide symporter from Arabidopsis. Plant Physiol. 131:70-77.

Schweizer, P., Christoffel, A., and Dudler, R. 1999. Transient expression of members of the germin-like gene family in epidermal cells of wheat confers disease resistance. Plant J. 20:541-552.

Shannon, P., Markiel, A., Ozier, O., Baliga, N. S., Wang, J. T., Ramage, D., Amin, N., Schwikowski, B., and Ideker, T. 2003. Cytoscape: A software environment for integrated models of biomolecular interaction networks. Genome Res. 13:2498-2504.

Souer, E., van Houwelingen, A., Kloos, D., Mol, J., and Koes, R. 1996. The No Apical Meristem gene of Petunia is required for pattern formation in embryos and flowers and is expressed at meristem and primordia boundaries. Cell 85:159-170.

Soukas, A., Cohen, P., Socci, N. D., and Friedman, J. M. 2000. Leptin-specific patterns of gene expression in white adipose tissue. Genes Dev. 14:963-980.

Staswick, P. E., Su, W., and Howell, S. H. 1992. Methyl jasmonate inhibition of root growth and induction of a leaf protein are decreased in an Arabidopsis thaliana mutant. Proc. Natl. Acad. Sci. U.S.A. 89:68376840

Stein, M., Dittgen, J., Sanchez-Rodriguez, C., Hou, B. H., Molina, A. Schulze-Lefert, P., Lipka, V., and Somerville, S. 2006. Arabidopsis PEN3/PDR8, an ATP binding cassette transporter, contributes to nonhost resistance to inappropriate pathogens that enter by direct penetration. Plant Cell 18:731-746.

Tao, Y., Xie, Z., Chen, W., Glazebrook, J., Chang, H., Han, B., Zhu, T., Zou, G., and Katagiri, F. 2003. Quantitative nature of Arabidopsis responses during compatible and incompatible interactions with the bacterial pathogen Pseudomonas syringae. Plant Cell 15:1-14.

Thilmony, R., Underwood, W., and He, S.Y. 2006. Genome-wide transcriptional analysis of the Arabidopsis thaliana interaction with the plant pathogen Pseudomonas syringae pv. tomato DC3000 and the human pathogen Escherichia coli O157:H7. Plant J. 46:34-53.

Thomma, B. P. H. J., Penninckx, I. A. M. A., Cammue, B. P. A., and Broekaert, W. F. 2001. The complexity of disease signaling in Arabidopsis. Curr. Opin. Immunol. 13:63-68.

Thomma, B. P. H. J., van Esse, H. P., Crous, P. W., and de Wit, P. J. G. M. 2005. Cladosporium fulvum (syn. Passalora fulva), a highly specialized plant pathogen as a model for functional studies on plant pathogenic Mycosphaerellaceae. Mol. Plant Pathol. 6:379-393.

Thordal-Christensen, H. 2003. Fresh insights into processes of nonhost resistance. Curr. Opin. Plant Biol. 6:351-357.

Tian, M., Win, J., Song, J., van der Hoorn, R. A. L., van der Knaap, E., and Kamoun, S. 2007. A Phytophthora infestans cystatin-like protein targets a novel tomato papain-like apoplastic protease. Plant Physiol. 143:364-377.

Valls, M., Genin, S., and Boucher, C. 2006. Integrated regulation of the type III secretion system and other virulence determinants in Ralstonia solanacearum. PLoS Pathog. 2:e82.

van Baarlen, P., van Esse, H. P., Siezen, R. J., and Thomma, B. P. H. J. 2008. Challenges in plant cellular pathway reconstruction based on gene expression profiling. Trends Plant Sci. 13:44-50.

van Esse, H. P., Bolton, M. D., Stergiopoulos, I., de Wit, P. J. G. M., and Thomma, B. P. H. J. 2007. The chitin-binding Cladosporium fulvum effector protein Avr4 is a virulence factor. Mol. Plant-Microbe Interact. 20:1092-1101.

van Esse, H. P., van't Klooster, J. W., Bolton, M. D., Yadeta, K. A., Van Baarlen, P., Boeren, S., Vervoort, J., de Wit, P. J. G. M., and Thomma, B. P. H. J. 2008. The Cladosporium fulvum virulence protein Avr2 inhibits host proteases require for basal defense. Plant Cell 20:19481963.

van Loon, L. C., and van Strien, E. A. 1999. The families of pathogenesisrelated proteins, their activities, and comparative analysis of PR-1 type proteins. Physiol. Mol. Plant. Pathol. 55:85-97.

van Wees, S. C. M., Chang, H., Zhu, T., and Glazebrook, J. 2003. Characterization of the early response of Arabidopsis to Alternaria brassicicola infection using expression profiling. Plant Physiol. 132:606-617.

Veronese, P., Narasimhan, M. L., Stevenson, R. A., Zhu, J.-K., Weller, S. C., and Bressan, R. A. 2003. Identification of a locus controlling severity of Verticillium disease in Arabidopsis thaliana. Plant J. 35:574-587.

Wan, J., Dunning, F. M., and Bent, A. F. 2002. Probing plant-pathogen interactions and downstream defense signaling using DNA microarrays. Funct. Integr. Genomics 2:259-273.

Wang, D., Pajerowska-Mukhtar, K., Culler, A. H., and Dong, X. 2007. 
Salicylic acid inhibits pathogen growth in plants through repression of the auxin signaling pathway. Curr. Biol. 17:1784-1790.

Wang, G., Ellendorff, U., Kemp, B., Mansfield, J. W., Forsyth, A., Mitchell, K., Bastas, K., Liu, C. M., Woods-Tör, E., Zipfel, C., de Wit, P. J. G. M., Jones, J. D. G., Tör, M., and Thomma, B. P. H. J. 2008. A genome-wide functional investigation into the roles of receptor-like proteins in Arabidopsis. Plant Physiol. 147:503-517

Wei, Y., Zhang, Z., Andersen, C. H., Schmelzer, E., Gregersen, P. L., Collinge, D. B., Smedegaard-Petersen, V., and Thordal-Christensen, H. 1998. An epidermis/papilla-specific oxalate oxidase-like protein in the defence response of barley attacked by the powdery mildew fungus. Plant Mol. Biol. 36:101-112.

Wise, R. P., Moscou, M. J., Bogdanove, A. J., and Whitham, S. A. 2007. Transcript profiling in host-pathogen interactions. Annu. Rev. Phytopathol. 45:329-369.

Wyatt, R. E., Ainley, W. M., Nagao, R. T., Conner, T. W., and Key, J. L. 1993. Expression of the Arabidopsis -ATAUX-11 auxin responsive gene in transgenic plants. Plant Mol. Biol. 22:731-749.

Zhong, R., and Ye, Z. H. 2007. Regulation of cell wall biosynthesis. Curr. Opin. Plant Biol. 10:564-572.

Zimmerli, L., Stein, M., Lipka, V., Schulze-Lefert, P., and Somerville, S. 2004. Host and non-host pathogens elicit different jasmonate/ethylene responses in Arabidopsis. Plant J. 40:633-646.

\section{AUTHOR-RECOMMENDED INTERNET RESOURCES}

ArrayExpress: www.ebi.ac.uk/microarray-as/ae

BioConductor, an open source software for bioinformatics: www.bioconductor.org

BioNetBuilder plugin: err.bio.nyu.edu/cytoscape/bionetbuilder Java: www.java.com/en

RefSeq database: www.ncbi.nlm.nih.gov/RefSeq

TM4 microarray software suite: www.tm4.org/mev.html 